Department of Policy and Planning Sciences

\author{
Discussion Paper Series
}

No.1346

Bubbles and Information in Continuous Double Auction and Call Market: An Experiment

by

Hiromine SAKURAI and Eizo AKIYAMA

March 2017

UNIVERSITY OF TSUKUBA

Tsukuba, Ibaraki 305-8573

JAPAN 


\title{
Bubbles and Information in Continuous Double Auction and Call Market: An Experiment
}

\author{
Hiromine Sakurai ${ }^{a, 1}$, Eizo Akiyama ${ }^{b}$ \\ a Department of policy and planning sciences, Graduate school of systems and information \\ engineering, University of Tsukuba, Tennodai 1-1-1, Tsukuba, Ibaraki 305-8573, Japan \\ ${ }^{b}$ Faculty of Engineering, Information and Systems, University of Tsukuba, Tennodai 1-1-1, \\ Tsukuba, Ibaraki 305-8573, Japan
}

\begin{abstract}
To assess the effects of informational asymmetry among traders and of type of market institution on the emergence of price bubbles in asset markets, we investigate price dynamics in experimental markets not only under continuous double auctions (CDAs) but also under call markets $(\mathrm{CMs})$. The results suggest that the effects of informational asymmetry on bubbles differ between CDAs and CMs. Specifically, informational asymmetry can contribute to the abatement of bubbles under CDAs as in Sutter et al. (2012), while it can contribute to promoting bubbles under CMs.

JEL classification: C91, G11

Key words: experiment, bubbles, trading institutions, asymmetric information
\end{abstract}

\section{Introduction}

Informational asymmetry among traders in asset markets is a non-negligible feature, and the trading behavior of insiders, who have informational advantages, affects the price dynamics, especially the emergence of bubbles and crashes. ${ }^{2}$ Tartaroglu's (2014) empirical study investigates the trading behavior of insiders during the technology bubble of the late 1990s and reports that the trading activity of insiders influenced the price dynamics during this period. ${ }^{3}$ Allen et al.'s (1993) theoretical study presents a finite period general equilibrium model of an exchange economy with asymmetric information. In their model, it is a necessary condition for a "strong bubble" that "each agent must have private information in the period and state in which the bubble occurs". ${ }^{4}$

The question then arises, how does informational asymmetry that exists between insiders and outsiders affect bubbles, which are persistent deviations in price from the underlying asset's fundamental value (FV)?

The attempts to answer this question from the analyses of real markets involve two difficulties. First, it is difficult to accurately assess whether traders

\footnotetext{
${ }^{1}$ Corresponding Author.

Email addresses: hiromine.sakurai@gmail.com (Hiromine Sakurai), eizo@sk.tsukuba.ac.jp (Eizo Akiyama)

${ }^{2}$ Camerer (1989) discusses that "When traders have different information or different models of their economic world, it is possible for prices to deviate from intrinsic value (based on their pooled information)"

${ }^{3}$ Tartaroglu (2014) defines insiders as "the top management of firms (CEO, Chair, President, Officers and Board of Directors)."

4In Allen et al.'s (1993) model, some agents' private information is not always known to other agents. Thus, information is asymmetrically distributed among the agents.
} 
have private information and what kind of information they have. Second, it is difficult to figure out what's the FV of an asset in real markets. An effective approach to solving these problems is experimental methods, ${ }^{5}$ whereby experimenters can assess and even manipulate the traders (subjects)' knowledge and the FV.

Smith et al. (1988) reports the emergence of large bubbles and crashes in laboratory asset markets, where all traders know the FV. Subjects act as traders in multi-period asset markets in which holding an asset generates stochastic dividend streams. The FV is defined as the discounted present value of all future expected dividend payments under the assumption of risk neutrality. Although the dividend structure is common knowledge among the traders, the trading prices, on average, persistently deviate from the FV and then collapse toward the last period, i.e., the existence of bubbles and crashes is observed in the experimental markets. ${ }^{6}$ Numerous studies following Smith et al. (1988) report the robustness of bubbles and crashes in experimental markets. ${ }^{7}$

Sutter et al. (2012) is one of several representative studies investigating the impact of informational asymmetry on bubbles based on the experimental design of Smith et al. (1988). ${ }^{8}$ Interestingly, in Sutter et al.'s experiment, asymmetric distribution of information among traders reduces mispricing. In Sutter et al.'s design, informed (uninformed) traders have (do not have) private information about an asset's future dividends, and the trading institution is the "open-book continuous double auction" or "(open-book) CDA".

A key feature of the experimental design of Sutter et al. (2012) we would like to notice is that information about the realized prices and the limit orders of the other traders within the current period is available to all traders through the order book. ${ }^{9}$ Therefore, uninformed traders can partially infer private information by referring to the order book (which might contains information posted by informed traders, who have private information about the asset's

\footnotetext{
${ }^{5}$ Harrison and List (2004) discusses fundamental methodologies of the experimental approaches.

${ }^{6}$ Another famous observation in Smith et al. (1988) and numerous subsequent studies is the decrease in the deviation in trading prices from the FV as traders repeatedly participate in the same types of markets with the same participants. Regarding the effect of these traders' experiences on the emergence of bubbles, Dufwenberg et al. (2005) conducted further studies in experimental markets following Smith et al. (1988) and showed that the trading prices are close to the FV in markets where only some of the traders are experienced as well as in markets where all the traders are experienced.

${ }^{7}$ Porter and Smith (1994), Palan (2013), and Powell and Shestakova (2016) provide comprehensive reviews of the experimental studies following Smith et al. (1988).

${ }^{8}$ The effects of informational asymmetry on bubbles were investigated, based on the experimental design of Smith et al. (1988), in several studies other than Sutter et al. (2012). Similar to Sutter et al. (2012), Markstädter et al. (2014) show that the informational asymmetry drives market prices toward the FV. On the other hand, several experimental studies find that the presence of private information does not reduce bubbles. (e.g. King, 1991; Oechssler et al., 2011). Unlike Smith et al. (1988), many experimental studies have investigated the relationship between informational asymmetry among traders and market performance. These studies are comprehensively surveyed in Markstädter et al. (2014) and Morone and Nuzzo (2016)

${ }^{9}$ In the trading interface used by Sutter et al. (2012), "traders were informed about their endowment in cash and stocks, the future dividends (if applicable), the current period's trades, and the open order books for bids and asks. The prices of trades were also shown in a graphical chart". However, traders did not know which of the uninformed or informed traders had posted each order and traded each asset.
} 
future dividends) within the current period. ${ }^{10}$ In addition, informed traders may directly exploit their informational advantage by accepting limit orders against which they possibly arbitrage. These informed and uninformed traders' strategic actions through the order book would make them more aware of the $\mathrm{FV}$, and might lead to price convergence toward the FV and reduce mispricing, as discussed in Sutter et al. (2012). ${ }^{11}$ Hereafter, we refer to this decrease in mispricing, which is caused by the traders' strategic actions through the order book in a market with informational asymmetry, as "Abatement in the sense of Sutter et al. (2012)" or "Abatement". Based on the above, we conjecture that Abatement is likely (unlikely) to happen under open-book (closed-book) conditions.

Conversely, is there a possibility that informational asymmetry increases mispricing?

Here, we consider the possibility of increased mispricing caused by the "strategic uncertainty" that exists in markets with asymmetric information. Strategic uncertainty is uncertainty about other traders' behavior. In markets with informational asymmetry, it is difficult for uninformed traders to predict the behavior of informed traders, whose actions are based on private information. Furthermore, it might be difficult for informed traders to predict the behavior of uninformed traders because of the "curse of knowledge": it would be difficult for informed traders to ignore their private information to simulate the condition of uninformed traders. ${ }^{12}$ This increase in strategic uncertainty caused by informational asymmetry among traders can occur not only in experimental markets, but also in real markets.

Akiyama et al. (2013) reports that strategic uncertainty induces mispricing in experimental markets employing the structure proposed by Smith et al. (1988). They report that initial forecast deviations from the FV are caused by strategic uncertainty, as well as individual bounded rationality. ${ }^{13}$ However, in their experimental design, strategic uncertainty is not induced by informational asymmetry, but by the inflow of new traders. It has not been shown whether informational asymmetry enhances strategic uncertainty.

If informational asymmetry among traders increase strategic uncertainty, it would promote bubbles, according to Akiyama et al. (2013). This effect of informational asymmetry on price dynamics is different from and in the opposite direction to Abatement. In the open-book markets of Sutter et al. (2012), the order book would complement the information about the other traders' behaviors, and thus reduce strategic uncertainty.

The increase in strategic uncertainty caused by informational asymmetry might enhance bubbles in closed-book markets, where Abatement is expected to be less likely to occur. The main purpose of our paper is to test the following

\footnotetext{
${ }^{10}$ Uninformed traders might infer from the seemingly high (low) limit prices or trading prices of the other traders that the asset's future dividends, which only the informed traders know, are high (low). However, such an inference by uninformed traders would not always be correct.

${ }^{11}$ Sutter et al. (2012) concludes that such strategic actions emerge based on the number of limit and market orders posted and the intraperiod convergence of the trading price from FV.

${ }^{12}$ Regarding the "curse of knowledge", Camerer et al. (1989) notes that "Better-informed agents are unable to ignore private information even when it is in their interest to do so; more information is not always better."

${ }^{13}$ Akiyama et al. (2013) elicits subjects' expectations about future prices as in Haruvy et al. (2007)
} 
conjecture: the effects of informational asymmetry on bubbles differs depending on the type of market. For this purpose, we basically use the same experimental structure used by Sutter et al. (2012), with the exception of trading institutions. We use not only a CDA, which is the trading institution employed in Sutter et al. (2012), but also a "closed-book call market" or "(closed-book) CM". A CM is a trading institution operating under closed-book conditions and has often been used in experimental studies following Smith et al. (1988). ${ }^{14}$ Van Boening et al. (1993) reports that in the framework of Smith et al. (1988), price bubbles are observed in the experimental markets under CMs, as well as under CDAs. ${ }^{15}$ In our experiments, it is expected that markets operating under a CDA (CM) discourage (promote) bubbles through Abatement (the effect of the increase in strategic uncertainty) if the traders' information is asymmetrically distributed.

Thus, we propose the following hypotheses.

HYPOTHESIS 1. Informational asymmetry contributes to reducing bubbles in experimental markets employing an open-book continuous double auction.

HYPOTHESIS 2. Informational asymmetry contributes to promoting bubbles in experimental markets employing a closed-book call market.

To confirm that our experimental settings are able to replicate Abatement, we examine Hypothesis 1. Hypothesis 2 states that the increase in strategic uncertainty caused by informational asymmetry enhances bubbles, as expected. We test these hypotheses by comparing price dynamics between the market with asymmetric distribution of information among traders and the market with symmetric distribution of information among traders for each trading institution. ${ }^{16}$

\section{Experimental Design}

In our experimental design, we basically used the same parameterizations and treatments as Sutter et al. (2012), but we employed not only an open-book continuous double auction, the trading institution used in Sutter et al. (2012), but also a closed-book call market.

\subsection{Basic Design of Our Experimental Markets}

In our experiments, subjects participated in experimental asset markets as traders, and were able to buy and/or sell the assets of a fictional company. Each market operated for four rounds, with each round consisting of 10 trading periods. Asset trading was organized under either a (open-book) CDA or a (closed-book) CM. No trader was allowed to purchase on credit or to sell

\footnotetext{
${ }^{14}$ For example, Van Boening et al. (1993), Haruvy et al. (2007), Lugovskyy et al. (2011), Akiyama et al. (2013), Akiyama et al. (2014), and Baghestanian et al. (2015) use a CM.

${ }^{15}$ In addition to Van Boening et al. (1993), Lugovskyy et al. (2011) studies experimental asset markets using the framework of Smith et al. (1988) under both CDAs and CMs and reports that "In a setting employing double auctions and call markets as trading institutions, bubbles and crashes are a quite robust phenomenon."

${ }^{16}$ Furthermore, we investigated the effect of informational asymmetry on individuals' expectations in relation to future prices. We elicited traders' predictions regarding future price trajectories using the basically same method as that used by Haruvy et al. (2007). We confirmed that this elicitation process did not essentially change our results because the price dynamics in our experimental markets were similar to those in the previous studies (Smith et al., 1988; Van Boening et al., 1993; Sutter et al., 2012). We present the methods and the results of the elicitation of traders' predictions in Appendix, Section A.
} 
short. Cash and asset holdings were carried over to the next period within a round. When a new round started, cash and asset holdings were initialized to the original starting levels.

Each unit of the asset paid a stochastic dividend at the end of each period. This dividend was either 0 or 20 experimental currency units (MARKs), each with 0.5 probability. The realized dividend was the same for all assets in a given period. After traders received their dividend at the end of 10th period of a round, the asset provided no further cash in a round, meaning that the "buyout" figure was zero. Thus, at the end of each round, the value of all assets was zero.

The expected dividend in every period was 10 MARKs $(=0$ MARKs $\times$ $0.5+20$ MARKs $\times 0.5)$. The asset's fundamental value $(\mathrm{FV})$ in any period $t$ was the expected dividend (10 MARKs) multiplied by the number of periods remaining $(11-t)$. This value decreased linearly from 100 MARKs in period 1 to 10 MARKs in period 10.

Each market consisted of six traders, and these groupings remained unchanged during the four rounds. At the beginning of each round, three traders in each market were endowed with 10 assets and 3000 MARKs, while the other three traders were endowed with 30 assets and 1000 MARKs.

\subsection{Information Levels and Treatments}

In our experiment, each trader was allocated to one of two information levels: " 0 " or "1". The difference between the two types of traders was their knowledge about the dividend at the end of the current period.

Traders with information level 0 did not know about the future dividend. At the beginning of period $t$, the asset's dividend for period $t$ was unknown to them. Only after trading in period $t$ were they informed of and then provided the dividend for period $t$.

On the other hand, traders with information level 1 knew about the asset's dividend for the current period in advance. At the beginning of period $t$, they were informed of the asset's dividend for period $t$, which they received at the end of period $t$.

The FV, which was determined by the sum of all expected future dividend payments, differed for traders with different information levels. Specifically, the FV in period $t$ of round $r$ in market $m$ for traders with information level 0 , who had no information about the future dividends, was defined as:

$$
F V_{t, r, m}^{0}=10 \times(11-t),
$$

which was the same as the previous definition of FV, and only depended on the period in question. On the other hand, the FV for traders with information level 1, who knew the dividend for the current period in advance, was defined as:

$$
F V_{t, r, m}^{1}=10 \times(10-t)+d i v_{t, r, m},
$$

where $d i v_{t, r, m}$ was the dividend per asset in period $t$ of round $r$ in market $m$. Based on the distribution of traders with information level 0 or 1 in the market, we used the different values of $\mathrm{FV}\left(F V^{0}\right.$ and $\left.F V^{1}\right)$ in our analyses.

The distributions of the traders with these information levels ( 0 or 1$)$ determined our experimental treatments. Our experimental design consisted of three 
treatments: "CONTROL", "SYMM," and "ASYMM". All traders in CONTROL markets had information level 0. All traders in SYMM markets had information level 1, whereby information about future dividends was symmetrically distributed among traders. Each ASYMM market consisted of three traders with information level 0 and three traders with information level $1 .{ }^{17}$ Each trader's information level was randomly determined at the beginning of the experiment and did not change during the four rounds.

There was the informational asymmetry in ASYMM, ${ }^{18}$ but not in CONTROL or SYMM. In ASYMM, at the beginning of each period, the three traders with information level 1 were informed in advance about the payment of a dividend for the current period, while the three traders with information level 0 were not given this information. Thus, information about future dividends was asymmetrically distributed among traders during each trading period in ASYMM.

All traders in every treatment knew the distribution of information levels in the market in which they participated and their own information level. ${ }^{19}$

\subsection{Trading Institutions}

Each of the three treatments described above was applied to both types of trading institution: (open-book) CDA and (closed-book) CM. We basically followed previous representative experimental studies in implementing each of the trading systems (CDAs and CMs). ${ }^{20}$ The details of each trading system we applied are shown in Appendix, Section B (experimental instructions).

In markets employing CDAs, the arrays of bids and asks (limit orders) that were posted in the current period were publicly displayed through the order book. A market order that accepted a limit order submitted by another trader made a contract. The order book contained the arrays of bids and asks sorted by price, and the transactions in time order, and was automatically updated as soon as new limit orders were posted or new market orders were posted (i.e., new contracts were made). Traders were not told which other traders had submitted particular limit and market orders. ${ }^{21}$ Thus, in ASYMM markets, which had a mixture of uninformed and informed traders, under a CDA, any trader was not able to know the information level of the trader who had posted a limit or market order.

In $\mathrm{CMs}$, all transactions in a period occurred at a single calculated price rather than the multiple prices resulting from traders posting bids or asks. All bids to buy (asks to sell) were limit orders submitted by traders nominating the highest (lowest) price at which they were willing to buy (sell) and the quantity. In each period, traders were only able to post one bid and ask at the same time.

\footnotetext{
${ }^{17}$ The ASYMM treatment is called "ASYMM1" by Sutter et al. (2012).

${ }^{18}$ Sutter et al. (2012) use two other treatments with the informational asymmetry among traders apart from ASYMM, although "there is no significant difference ... across the three treatments with asymmetric information" (Sutter et al., 2012).

${ }^{19}$ The term "information level" was not used in the instructions for CONTROL and SYMM markets. Traders were only told that all the information displayed on their screen was publicly known.

${ }^{20}$ We implemented the CDAs' systems following those in Sutter et al. (2012). Also, the CMs' systems we used followed those in Haruvy et al. (2007).

${ }^{21}$ The trader's own bids/asks were displayed in blue and those of the other traders were displayed in black. In addition, the trader's own transactions were shown in a separate area of the screen to the order book.
} 
Traders were not informed of the other traders' limit orders under CMs, unlike under CDAs.

Under CMs, all bids and asks submitted by traders in each period were aggregated into demand and supply curves. All trades had occurred at the trading price where the market was cleared. ${ }^{22}$ The bids (asks) whose prices on order were equal to or higher (lower) than that price were accepted.

Under CDAs, traders traded assets during the current period through the order book, which provided information regarding limit orders and transactions executed by traders. On the other hand, under CMs, all transactions occurred at the price calculated by the computer after all traders had posted their buy and sell orders in the period. As noted in the introduction, the information about the orders and the realized trades that was available only CDAs was expected to promote Abatement (in the sense of Sutter et al., 2012) and reduce strategic uncertainty in markets with the informational asymmetry.

\subsection{Experimental Procedures}

We conducted six markets for each of six kinds of settings (= three treatments $\times$ two trading institutions). Thus, we ran 36 markets.

Before the experiments commenced, we predetermined the dividend following the procedure used in Sutter et al. (2012). (The manner of this procedure and the values of all the dividends used in our experimental markets are shown in Appendix, Section C.) In this way, in each period of each round, the mean value of the realized dividend ( 0 or 20 ) in the six markets of each kind of setting (three treatments, two trading institutions) was identical to the expected value of the dividend (10). Thus, the mean of $F V_{t, r, m}^{1}\left(=10 \times(10-t)+d i v_{t, r, m}\right.$, where $\operatorname{div}_{t, r, m}$ was the realized dividend in period $t$ of round $r$ in market $m$ ) over the six markets for each setting (three treatments, two trading institutions) was identical to the (mean) $F V_{t, r, m}^{0}(=10 \times(11-t))$.

Our experimental markets were computerized using z-Tree (Fischbacher, 2007). As outlined above, we implemented 36 markets in which 215 subjects participated. ${ }^{23}$ The subjects were undergraduate or graduate students at the University of Tsukuba and Ibaraki Prefectural Tsukuba School of Nursing who had no experience in experimental asset markets. We conducted our experiments between November 2015 and September 2016.

Subjects read the instructions (See Appendix, Section B) and practiced using the trading interfaces before the experiment started. Each experimental session took, on average, approximately three and a half hours. After the experiments were finished, earnings were paid to each subject in accordance with the sum of his cash holdings (MARKs) at the end of each round. Each MARK was converted to 0.2 yen. On average, subjects received 4000 yen (about 33.4 US dollars at the time we conducted the experiments) including a 500 yen participation fee. 24

\footnotetext{
${ }^{22}$ This process determined the price that maximizes the trading volume. When there was a price range where the trading volume was maximized, the lowest price in this price range was chosen as the trading price.

${ }^{23} \mathrm{Six}$ subjects participated in each of 35 experimental markets we conducted. The remaining market consisted of five subjects because one person canceled at the last minute.

${ }^{24}$ We elicited traders' predictions regarding future price trajectories before the trades of assets in each period started, and traders were awarded a prediction bonus (MARKs) at the end of each round. The average duration and earnings in our experiment contained the
} 


\section{Results}

The average trading price dynamics under open-book continuous double auction for each treatment are shown in Figure 1, with period on the horizontal axis and price on the vertical axis. ${ }^{25}$ The single-transaction price dynamics under closed-book call market for each treatment are shown in Figure 2. In Figs. 1 and 2, the dashed gray line, solid gray line, and dashed black line represent the mean value of the market prices in the CONTROL, SYMM, and ASYMM treatments, respectively. The market price under a (open-book) CDA (Fig. 1) is the average trading price in each period, while that under a (closed-book) CM (Fig. 2) is the single-transaction price in each period. The solid black line represents the asset's fundamental value $(\mathrm{FV}) .{ }^{26}$

Figure 1: Mean price dynamics in open-book continuous double auctions for each treatment

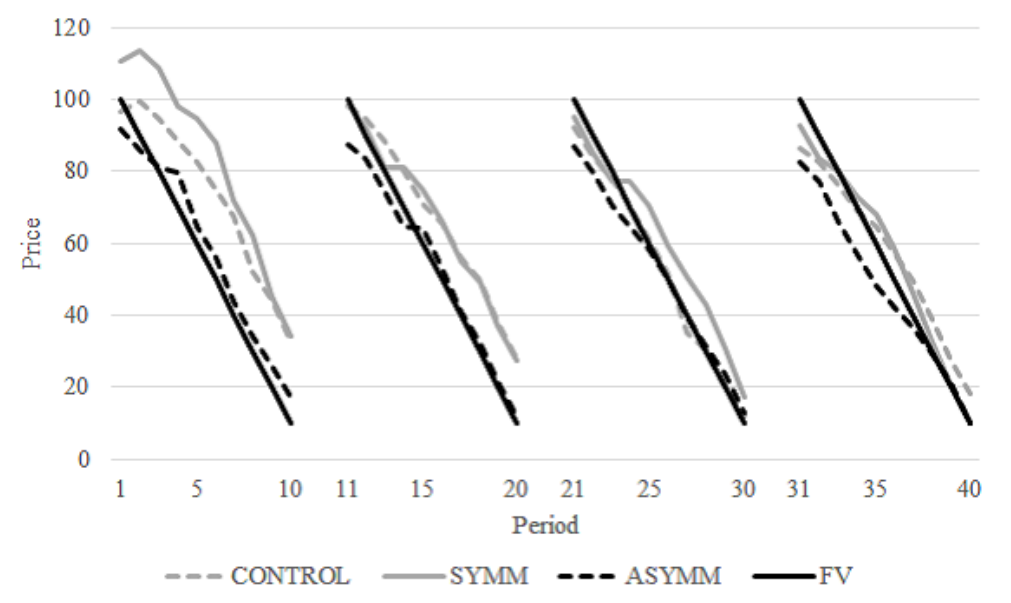

Figure 3 shows the price dynamics in each of six individual markets in round one of each treatment (CONTROL, SYMM, and ASYMM) under each trading institution (CDA and CM). In each panel, the gray lines show the price trajectories in each of the six individual markets, while the black line represents the FV. 27

Under CDA (Fig. 1), the deviations in prices from FV in CONTROL markets seem to decrease as traders gain experience across rounds. This is a typical pattern in the experiments of Smith et al. (1988) and numerous subsequent studies. The price dynamics in ASYMM is closer to FV than that in $\mathrm{CON}$ -

\footnotetext{
eliciting period and the prediction bonus respectively.

${ }^{25}$ Each market had four rounds, each round consisting of 10 trading periods. Thus, each market consisted of 40 periods.

${ }^{26}$ The solid black lines in both Figs. 1 and 2 represent the FV not only for traders with information level $0\left(F V^{0}\right)$, but also for traders with information level $1\left(F V^{1}\right)$. This is because, as in Section 2.4, the mean of $F V^{1}$ over the six markets for each setting (three treatments, two trading institutions) was identical to the (mean) $F V^{0}$.

${ }^{27}$ Similar to Figs. 1 and 2 , the FV (black line) in each panel in Fig. 3 is identical to not only the mean $\mathrm{FV}$ for traders with information level 0 , but also to that for traders with information level 1 .
} 
Figure 2: Mean price dynamics in closed-book call markets for each treatment

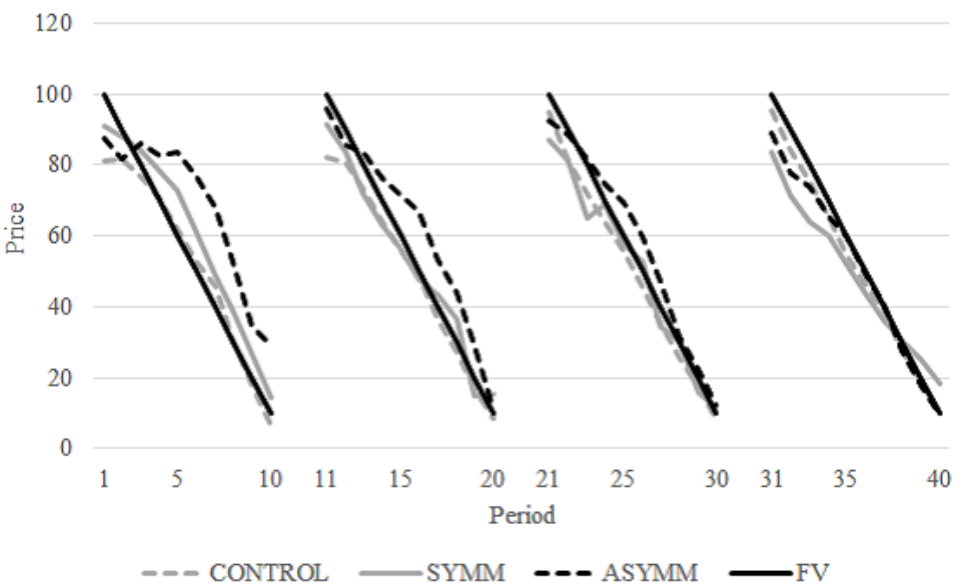

TROL or SYMM, which suggests that informational asymmetry abates bubbles in markets under CDAs. This difference in price dynamics among the treatments supports the results of Sutter et al. (2012). The observation in Fig. 1 supports Hypothesis 1: informational asymmetry contributes to abating bubbles in experimental markets employing a CDA.

Under CMs (Fig. 2), the deviations in mean prices from FV in CONTROL markets are very small. On the other hand, in the price chart for round 1 in each CONTROL market under a CM (lower left chart in Fig. 3), bubbles can emerge, as observed in Van Boening et al. (1993). Furthermore, bubbles occur less frequently in the CONTROL markets under CMs than in those under CDAs, ${ }^{28}$ which is consistent with that discussed in Sunder et al. (1992). It points out that "While call markets may discover the equilibrium price more precisely, continuous double auctions may have the advantage of faster (albeit less precise) discovery of price during the inter-call periods when the call market leaves the price undefined."

In CMs, the deviations in transaction prices from FV in ASYMM appear to be larger than those in CONTROL or SYMM. This is in contrast to the case of markets under CDAs, suggesting that informational asymmetry promotes bubbles in CMs. Thus, Fig. 2 supports Hypothesis 2: informational asymmetry contributes to promoting bubbles in experimental markets employing a CM.

We measured and compared the bubbles in terms of the asset's mispricing and overvaluation, following Stöckl et al. (2010), who defined the relative absolute deviation (RAD) as the index of the asset's mispricing and the relative deviation (RD) as the index of the asset's overvaluation. ${ }^{29}$ RAD and RD were

\footnotetext{
${ }^{28}$ Numerous experimental studies have compared the performance of the markets under CDAs with that under CMs. These studies are comprehensively surveyed in Sunder et al. (1992), Powell and Shestakova (2016) and Morone and Nuzzo (2016). In experimental asset markets with asymmetric information, the performance between CDAs and CMs has been compared in several experimental studies, where the focus is on aspects other than the effect of informational asymmetry on the emergence of bubbles (Liu, 1996; Schnitzlein, 1996; Morone and Nuzzo, 2015).

${ }^{29}$ According to Stöckl et al. (2010), RAD and RD fulfill the three features that it "seems
} 
Figure 3: Trading price dynamics in round one of each treatment under each trading institution

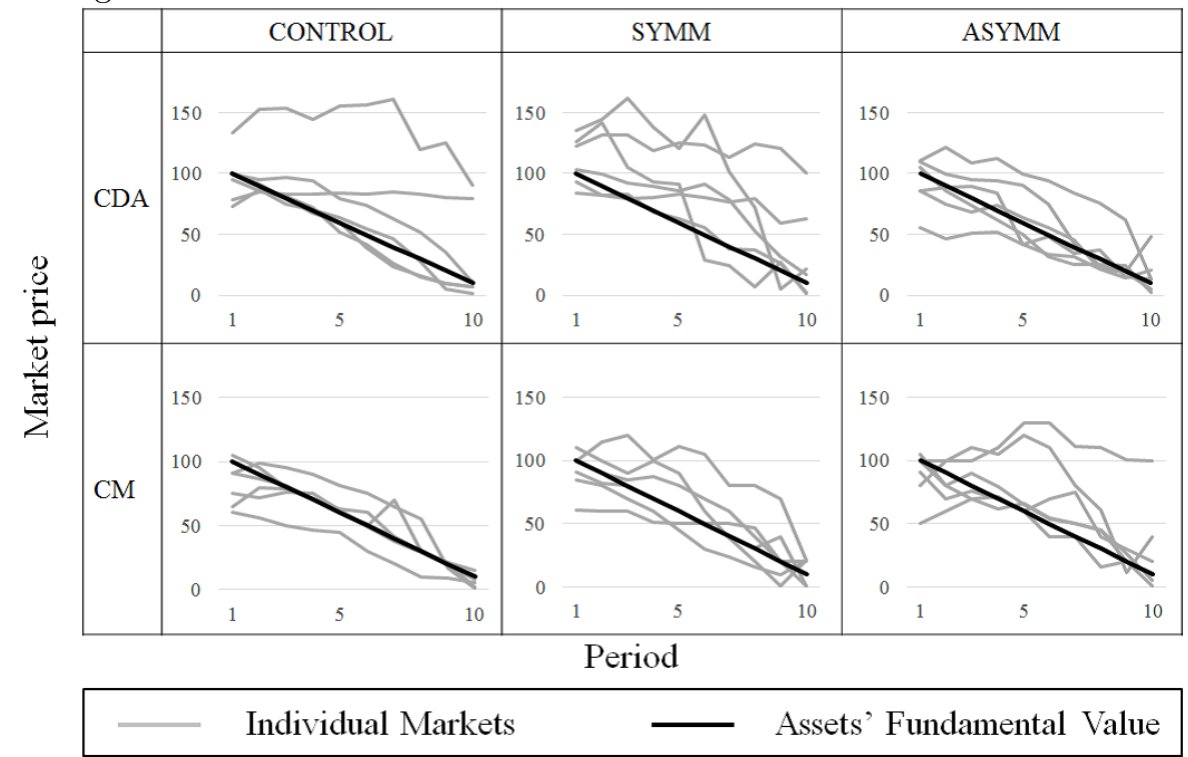

determined as follows:

$$
\begin{aligned}
& R A D_{r, m}=\sum_{t=1}^{10} \frac{\left|P_{t, r, m}-F V_{t, r, m}\right|}{\mid \overline{F V_{r, m} \mid}} \\
& R D_{r, m}=\sum_{t=1}^{10} \frac{\left(P_{t, r, m}-F V_{t, r, m}\right)}{\mid \overline{F V_{r, m} \mid},}
\end{aligned}
$$

where $P_{t, r, m}$ was the average price (single-transaction price) in period $t$ of round $r$ in market $m$ under a $\mathrm{CDA}(\mathrm{CM}), F V_{t, r, m}$ was the $\mathrm{FV}$ in period $t$ of round $r$ in market $m$, and $\overline{F V}_{r, m}$ was the average $\mathrm{FV}$ over all periods in round $r$ in market $m$. For $F V_{t, r, m}$, we used two different values of $\mathrm{FV}\left(F V^{0}\right.$ and $\left.F V^{1}\right)$ in the treatments (CONTROL, SYMM, and ASYMM). The FV for traders with information level $0\left(F V_{t, r, m}^{0}\right)$ was used in CONTROL, and that for traders with information level $1\left(F V_{t, r, m}^{1}\right)$ was used in SYMM and ASYMM. ${ }^{30}$ Likewise, for $F V_{t, r, m}, \overline{F V}_{r, m}$ in CONTROL (SYMM and ASYMM) was calculated using $F V^{0}\left(F V^{1}\right)$. The increase (decrease) in the value of both RAD and RD means

sensible to require" for bubble-related measures: the measures should "(i) relate the fundamental value and price, (ii) be monotone in the difference between fundamental value and price, and (iii) be independent of the total number of periods and the absolute level of fundamental value." Thus, a number of studies have conducted analyses where RAD and/or RD are calculated to measure bubbles (see, for example, Kirchler et al., 2012; Sutter et al., 2012; Cheung et al., 2014; Akiyama et al., 2013; Markstädter et al., 2014; Baghestanian et al., 2015).

${ }^{30} \mathrm{In}$ addition to the analyses where RAD and RD based on $F V^{1}$ were used in ASYMM, we conducted analyses where RAD and RD based on $F V^{0}$ were used in ASYMM. We obtained similar results in both analyses regardless of the difference between $F V^{0}$ and $F V^{1}$ (See Appendix, Section D). 
that the assets are more likely to be overvalued (undervalued) and traded at prices distant from (close to) FV: thus, bubbles become larger (smaller).

We conducted regression analyses using the ordinary least squares method where the dependent variables were, in turn, RAD and RD. The independent variables in both of these regression analyses were a dummy for treatment ASYMM, a dummy for trading institution CDA, an interaction dummy between ASYMM and CDA, and a variable for the round. Table 1 presents a summary of these analyses.

Table 1: The effects of informational asymmetry on bubbles under each trading institution

\begin{tabular}{lcc}
\hline & Model1 & Model2 \\
\hline Dependent value & RAD & RD \\
\hline Constant & $0.33^{* * *}$ & $0.16^{* *}$ \\
& $(0.05)$ & $(0.07)$ \\
ASYMM dummy & $0.12^{* *}$ & $0.14^{*}$ \\
& $(0.06)$ & $(0.07)$ \\
CDA dummy & $0.14^{* * *}$ & $0.23^{* * *}$ \\
& $(0.05)$ & $(0.06)$ \\
Round & $-0.06^{* * *}$ & $-0.08^{* * *}$ \\
& $(0.02)$ & $(0.02)$ \\
ASYMM \& CDA dummy & $-0.21^{* *}$ & $-0.36^{* * *}$ \\
& $(0.08)$ & $(0.10)$ \\
Adjusted R & 0.12 & 0.17 \\
$\mathrm{~N}$ & 144 & 144 \\
\hline
\end{tabular}

Notes. This table shows a summary of the regression analyses where the dependent variables are RAD and RD for model 1 and model 2, respectively. The independent variables in both of these regressions are a dummy for treatment ASYMM, a dummy for trading institution CDA, an interaction dummy between ASYMM and CDA, and a variable for the round. The values of the intercepts in both of these models represent the effects of the baseline condition, where the informational asymmetry among traders does not exist (CONTROL and SYMM) and the trading institution is a CM. The sample size for each regression is 144 (=2 trading institutions $\times 3$ treatments $\times 6$ markets $\times 4$ rounds). These regression analyses use the ordinary least squares method. The standard error of each coefficient is included in parenthesis. *, **, and *** indicate significance at the $10 \%, 5 \%$, and $1 \%$ levels, respectively.

In Table 1, the coefficient of the ASYMM dummy in the regression of RAD (model 1 ) is significantly positive (two-sided t test, $p=0.030$ ). Also, that in the regression of RD (model 2) is weakly significantly positive (two-sided $\mathrm{t}$ test, $p=0.054$ ). These observations suggest that bubbles are promoted by informational asymmetry, which, as noted in the introduction, could be a source of strategic uncertainty: uncertainty about other traders' behavior.

The coefficients of the interaction dummy between ASYMM and CDA in both model 1 and model 2 are significantly negative (two-sided t test, $p=$ 0.010 and 0.000 , respectively), which means that under CDA, the informational asymmetry contributes to the abatement of bubbles, as found in Sutter et al. (2012). These results suggest that Hypothesis 1 is supported.

We conjecture that in the ASYMM markets under CDA, there are two kinds of negative effects of the information available in the order book on bubbles: (i) 
the order book's information about traders' behavior can suppress the strategic uncertainty caused by the informational asymmetry; and (ii) Abatement (in the sense of Sutter et al., 2012) occurs, that is, the traders' strategic actions through the order book in the market with the informational asymmetry make the traders more conscious of $\mathrm{FV}$, and lead to price convergence toward FV. ${ }^{31}$

On the other hand, in CMs, traders do not refer to the information in the order book. Thus, we conjecture that, under CMs, neither effect (i) nor effect (ii) outlined above is likely to occur, and thus the increase in strategic uncertainty caused by the informational asymmetry contributes promoting bubbles. The (weakly) significantly positive coefficients of the ASYMM dummy in model 1 and model 2, respectively, suggests that Hypothesis 2 is (weakly) supported.

From the above, it is clear that the effects of the informational asymmetry on price dynamics are significantly different between markets under CDAs and CMs.

\section{Discussion}

To test how the difference in trading institutions affects the effects of informational asymmetry on the emergence of bubbles, we investigated experimental markets using both an open-book continuous double auction, which is the trading institution employed by Sutter et al. (2012), and a closed-book call market.

Comparing the price trajectories between the markets with asymmetric distribution of information among traders and those with symmetric distribution of information among traders, under (open-book) CDAs we found that bubbles are abated when the informational asymmetry exists. This result is consistent with the findings of Sutter et al. (2012). Conversely, bubbles are facilitated in the markets under (closed-book) CMs with the informational asymmetry. We conducted statistical analyses and found that the informational asymmetry itself, which could be a source of strategic uncertainty as discussed in the introduction, contributes to promoting bubbles. In CMs, traders do not refer to the information in the order book during a period, and "Abatement" in the sense of Sutter et al. (2012) is unlikely to occur. We conjecture that this is why the increase in strategic uncertainty attributed to the informational asymmetry only contributes to promoting bubbles in CMs. On the other hand, in CDAs, the informational asymmetry contributes to reducing bubbles, which implies that Abatement occurs. It is clear that the effects of the informational asymmetry on bubbles are significantly different between markets under CDAs and CMs.

As discussed in Sutter et al. (2012), it is likely that Abatement occurs in real markets with asymmetric distribution of information among traders. On the other hand, as shown in our study, high levels of strategic uncertainty caused by informational asymmetry can promote mispricing. This conjecture has an interesting connection with the underpricing of initial public offerings (IPOs), ${ }^{32}$

\footnotetext{
${ }^{31}$ As noted in the introduction, the actions of uninformed and informed traders are as follows: uninformed traders can partially infer the private information by referring to the order book (which might contains information posted by informed traders, who have private information about the asset's future dividends) within the current period. In addition, informed traders can exploit their informational advantage regarding FV by accepting limit orders against which they can possibly arbitrage.

${ }^{32}$ Ritter and Welch (2002) comprehensively review a number of studies of underpricing in IPOs.
} 
where the offer price falls below the initial price. The results of our study imply that strategic uncertainty attributed to informational asymmetry among traders could be one factor that leads traders to purchase shares in IPOs at a price higher than the offer price. ${ }^{33}$

\section{Acknowledgement}

Makoto Soga, Tomohiro Nishikawa and Junpei Yamazaki provided invaluable help in organizing the experiments. Comments and suggestions on our manuscript from Morimitsu Kurino, Ryoji Sawa and Ryuichiro Ishikawa, and bibliographic information given by Michael Kirchler, Matthias Sutter, Jürgen Huber are acknowledged. This project is partly supported by the experiments reported in this paper have been approved by Research Ethics Board of Faculty of Engineering, Information and Systems, University of Tsukuba (No. 2012R25-2). This work was supported by JSPS KAKENHI [Grant Numbers 26350415, 26285043, 26245026, 26289170].

\section{References}

Akiyama, E., Hanaki, N., and Ishikawa, R. (2013). It is not just confusion! strategic uncertainty in an experimental asset market. Strategic Uncertainty in an Experimental Asset Market (August 8, 2013).

Akiyama, E., Hanaki, N., and Ishikawa, R. (2014). How do experienced traders respond to inflows of inexperienced traders? an experimental analysis. Journal of Economic Dynamics and Control, 45:1-18.

Allen, F., Morris, S., and Postlewaite, A. (1993). Finite bubbles with short sale constraints and asymmetric information. Journal of Economic Theory, 61(2):206-229.

Baghestanian, S., Lugovskyy, V., and Puzzello, D. (2015). Traders' heterogeneity and bubble-crash patterns in experimental asset markets. Journal of Economic Behavior \& Organization, 117:82-101.

Camerer, C. (1989). Bubbles and fads in asset prices. Journal of Economic Surveys, 3(1):3-41.

Camerer, C., Loewenstein, G., and Weber, M. (1989). The curse of knowledge in economic settings: An experimental analysis. The Journal of Political Economy, pages 1232-1254.

Carter, R. and Manaster, S. (1990). Initial public offerings and underwriter reputation. The Journal of Finance, 45(4):1045-1067.

Cheung, S. L., Hedegaard, M., and Palan, S. (2014). To see is to believe: Common expectations in experimental asset markets. European Economic Review, 66:84-96.

\footnotetext{
${ }^{33}$ IPO markets are characterized by informational asymmetry among traders. Underpricing in IPO markets with informational asymmetry among traders has been investigated in numerous studies. See, for example, Rock (1986) and Carter and Manaster (1990).
} 
Dufwenberg, M., Lindqvist, T., and Moore, E. (2005). Bubbles and experience: An experiment. The American Economic Review, 95(5):1731-1737.

Fischbacher, U. (2007). z-tree: Zurich toolbox for ready-made economic experiments. Experimental economics, 10(2):171-178.

Harrison, G. W. and List, J. A. (2004). Field experiments. Journal of Economic literature, 42(4):1009-1055.

Haruvy, E., Lahav, Y., and Noussair, C. N. (2007). Traders' expectations in asset markets: experimental evidence. The American Economic Review, 97(5):1901-1920.

Hey, J. D. (1994). Expectations formation: Rational or adaptive or $\cdots$ ? Journal of Economic Behavior \& Organization, 25(3):329-349.

Hommes, C., Sonnemans, J., Tuinstra, J., and Van de Velden, H. (2005). Coordination of expectations in asset pricing experiments. Review of Financial studies, 18(3):955-980.

Huber, J. and Kirchler, M. (2012). The impact of instructions and procedure on reducing confusion and bubbles in experimental asset markets. Experimental Economics, 15(1):89-105.

King, R. R. (1991). Private information acquisition in experimental markets prone to bubble and crash. Journal of Financial Research, 14(3):197-206.

Kirchler, M., Huber, J., and Stöckl, T. (2012). Thar she bursts: Reducing confusion reduces bubbles. The American Economic Review, 102(2):865-883.

Liu, Y.-J. (1996). Auction mechanisms and information structure: an experimental study of information aggregation in securities markets. Research in Experimental Economics, 6:165-211.

Lugovskyy, V., Puzzello, D., Tucker, S., et al. (2011). An experimental study of bubble formation in asset markets using the tâtonnement trading institution. Department of Economics and Finance, College of Business and Economics, University of Canterbury.

Markstädter, A., Keser, C., et al. (2014). Informational asymmetries in laboratory asset markets with state dependent fundamentals. In Annual Conference 2014 (Hamburg): Evidence-based Economic Policy, number 100359. Verein für Socialpolitik/German Economic Association.

Morone, A. and Nuzzo, S. (2015). Market efficiency, trading institutions and information mirages: evidence from an experimental asset market.

Morone, A. and Nuzzo, S. (2016). Asset markets in the lab: a literature review.

Oechssler, J., Schmidt, C., and Schnedler, W. (2011). On the ingredients for bubble formation: informed traders and communication. Journal of Economic Dynamics and Control, 35(11):1831-1851.

Palan, S. (2013). A review of bubbles and crashes in experimental asset markets. Journal of Economic Surveys, 27(3):570-588. 
Porter, D. P. and Smith, V. L. (1994). Stock market bubbles in the laboratory. Applied Mathematical Finance, 1(2):111-128.

Powell, O. and Shestakova, N. (2016). Experimental asset markets: A survey of recent developments. Journal of Behavioral and Experimental Finance, $12: 14-22$.

Ritter, J. R. and Welch, I. (2002). A review of ipo activity, pricing, and allocations. The Journal of Finance, 57(4):1795-1828.

Rock, K. (1986). Why new issues are underpriced. Journal of financial economics, 15(1-2):187-212.

Schnitzlein, C. R. (1996). Call and continuous trading mechanisms under asymmetric information: An experimental investigation. the Journal of Finance, 51(2):613-636.

Smith, V. L., Suchanek, G. L., and Williams, A. W. (1988). Bubbles, crashes, and endogenous expectations in experimental spot asset markets. Econometrica: Journal of the Econometric Society, pages 1119-1151.

Stöckl, T., Huber, J., and Kirchler, M. (2010). Bubble measures in experimental asset markets. Experimental Economics, 13(3):284-298.

Sunder, S. et al. (1992). Experimental asset markets: A survey. Carnegie Mellon University.

Sutter, M., Huber, J., and Kirchler, M. (2012). Bubbles and information: An experiment. Management Science, 58(2):384-393.

Tartaroglu, S. (2014). Insider trading and net order flows: The case of technology bubble. Available at SSRN 1344812.

Van Boening, M. V., Williams, A. W., and LaMaster, S. (1993). Price bubbles and crashes in experimental call markets. Economics Letters, 41(2):179-185. 


\section{A Appendix: Analyses of Elicitations of Traders' Predictions}

In addition to testing these hypotheses, we investigate the effect of informational asymmetry on individuals' expectations of prices by eliciting traders' predictions regarding future price trajectories. ${ }^{34}$ For this purpose, we elicit traders' beliefs about prices as in Haruvy et al. (2007), whose elicitation method has been used in studies attempting to investigate traders' expectations (e.g., Akiyama et al., 2013, 2014; Markstädter et al., 2014; Baghestanian et al., 2015).

\section{A.1 Method of Elicitation of Subjects' Expectations}

Each trader in the variously treated markets (CONTROL, SYMM, or ASYMM) under each of the two trading institutions (open-book continuous double auction or closed-book call market) was asked to forecast the market price in future periods of the current round before the trades of assets in each period started. For example, before trades in period 6 started, each trader submitted five predictions of future market prices (for period 6 , period 7 , period 8 , period 9 , and period 10). In the (closed-book) CMs, the trading price calculated by the computer for each future period was the predictive target. On the other hand, in the markets under a (open-book) CDA, traders predicted the average trading price within a given period for each future period: the predictive target was the average trading price in a given period.

When forecasting the future price trajectory before the trades in each period started, each trader was provided with information about the history of market prices for all previous periods and rounds, the assets and cash holdings in the current period, and future dividends (if his information level was 1).

Traders were awarded a prediction bonus (MARKs) at the end of each round using the same incentive scheme as that used by Akiyama et al. (2013). ${ }^{35}$ Each trader's prediction bonus was determined as follows: prediction bonus for round $\mathrm{s}(\mathrm{MARKs})=0.5 \% \times($ the number of predicted prices that were within $10 \%$ of the actual market price in round $s$ ) $\times$ (trader's cash holding at the end of rounds). ${ }^{36}$ Each trader submitted 55 predictions in each round, i.e. the sum of all predictions in each period, from 10 in period 1 to one in period 10 . Thus, the maximum prediction bonus was $27.5 \%(0.5 \% \times 55)$, which occurred when all 55 predictions in a given round were within $10 \%$ of the actual market price. We used this incentive scheme to "reduce subjects' incentive to influence the prices to move closer to their forecasts by making losses" (Akiyama et al., 2013).

\section{A.2 Results of Traders' Belief Dynamics}

In our experiment, the informational asymmetry contributes to the abatement of bubbles in markets under a CDA. Conversely, the informational asymmetry

\footnotetext{
${ }^{34}$ Sutter et al. (2012) did not investigate traders' predictions regarding future prices. Markstädter et al. (2014) examined the correlation between predicted prices and realized prices in experimental markets with asymmetric information.

${ }^{35}$ The experimental currency MARK was converted into real money.

${ }^{36}$ In our experiment under CDAs, the market price (predictive target) is defined as the average trading price. Also, under $\mathrm{CMs}$, the market price is the single trading price calculated by the computer. Under both trading institutions, if no transactions occur, the market price is defined as the highest bid price in a given period.
} 
contributes to promoting bubbles in a CM. In the following analyses, we examine how traders develop their expectations of future price trajectories (beliefs) during trading.

We measured the deviations from the asset's fundamental value (FV) in the traders' predictions of future prices using two indexes: belief's relative absolute deviation (BRAD) and belief's relative deviation (BRD). ${ }^{37}$ BRAD and BRD are defined as follows:

$$
\begin{aligned}
& B R A D_{e, r, m}^{i}=\frac{1}{10-e+1} \sum_{p=e}^{10} \frac{\left|f_{e, p, r, m}^{i}-F V_{p, r, m}\right|}{\overline{F V}_{e, r, m}} \\
& B R D_{e, r, m}^{i}=\frac{1}{10-e+1} \sum_{p=e}^{10} \frac{\left(f_{e, p, r, m}^{i}-F V_{p, r, m}\right)}{\overline{F V}_{e, r, m}},
\end{aligned}
$$

where $f_{e, p, r, m}^{i}$ is the forecast of the asset price in period $p$ elicited by $i$ in period $e$ of round $r$ in market $m, F V_{p, r, m}$ is the $\mathrm{FV}$ in period $p$ of round $r$ in market $m$, and $\overline{F V}_{e, r, m}$ is the average $\mathrm{FV}$ over the remaining periods when elicited (from period e to 10) in round $r$ in market $m$. In calculating BRAD/BRD for each trader, $F V$ and $\overline{F V}$ were based on the trader's information level. Specifically, the $F V_{p, r, m}\left(\overline{F V}_{e, r, m}\right)$ used in the calculation of both BRAD and BRD for traders with information level 0 was set to (calculated based on) the FV for traders with information level 0. Similarly, the $F V_{p, r, m}\left(\overline{F V}_{e, r, m}\right)$ used in the calculation of both BRAD and BRD for traders with information level 1 was set to (calculated based on) the FV for traders with information level 1.

These two measures are the revised versions of RAD and RD, which are the bubble measures defined by Stöckl et al. (2010) for the evaluation of traders' predictions. Akiyama et al. (2013) defined bubble measures RAFD and RFD similar to BRAD and BRD to evaluate traders' beliefs. If BRAD, ${ }^{38}$ which is a positive value, is close to 0 , the trader forecasts the future price trajectory tracking the FV. A positive (negative) value of BRD means that the trader predicts future prices higher (lower) than $\mathrm{FV}$ on average.

We conducted regression analyses using the ordinary least squares method where the dependent variables were, in turn, BRAD and BRD. The regressions of BRAD/BRD for traders with information level 0 and those with information level 1 were carried out separately. The independent variables in both regressions were a dummy for treatment ASYMM, a dummy for trading institution CDA, an interaction dummy between ASYMM and CDA, a variable for the

\footnotetext{
${ }^{37}$ In Section E, we illustrate the traders' belief dynamics in each treatment (CONTROL, SYMM, and ASYMM) under each trading institution (CDA and CM) using three-dimensional bar charts following Haruvy et al. (2007).

${ }^{38}$ The only difference between the definitions of RFD (RAFD) and BRD (BRAD) is the manner of calculation of $\overline{F V}_{e, r, m}$, whereby the average (absolute) deviation of forecast prices from $\mathrm{FV}$ was used in the definitions of these indexes. The $\overline{F V}_{e, r, m}$ used in the definition of RAFD/RFD is the average FV over all periods (i.e., from period 1 to period 10). On the other hand, that used in the definition of BRAD/BRD is the average FV over all remaining periods (i.e., from period e to period 10). In the calculation of $B R D_{e, p, r, m}\left(B R A D_{e, p, r, m}\right)$, the average of the (absolute) deviations of the forecasts from FV in the remaining periods (from period $e$ to period 10) at period $e$ is normalized by the average $\mathrm{FV}$ in the remaining periods (from period $e$ to period 10) at period $e$, which is expected to clarify the changes in the traders' beliefs across periods.
} 
round, and a variable for the period. ${ }^{39}$ The sample size for the regressions for traders with information level 0 was 3852,40 and that for traders with information level 1 was 3888. Table 2 presents a summary of the analyses of $\mathrm{BRAD} / \mathrm{BRD}$ for traders with information level 0 and those with information level 1.

It can be seen from Table 2 that the coefficients of the ASYMM dummy in both the regressions of BRAD (model 3 and model 5) and those of BRD (model 4 and model 6) are significantly positive. This means that both traders with information level 0 and those with information level 1 are likely to forecast future price trajectories higher than $\mathrm{FV}$ in $\mathrm{CMs}$ with the informational asymmetry, where bubbles seem to be expanded. In addition, the coefficients of the interaction dummy between ASYMM and CDA in both the regressions of BRAD (model 3 and model 5) and those of BRD (model 4 and model 6) are significantly negative. This implies that both traders with information level 0 and those with information level 1 are likely to forecast future price trajectories tracking $\mathrm{FV}$ in markets with the informational asymmetry under CDAs, where bubbles seem to be abated. Under both CDAs and CMs, the effect of information asymmetry on traders' forecast price dynamics is in the same direction as that on the realized price dynamics. These correlations between traders' beliefs and the realized price dynamics support the observations of Haruvy et al. (2007) and Markstädter et al. (2014). The coefficient of the CDA dummy in both regressions of BRAD (model 3 and model 5) and those of BRD (model 4 and model 6 ) is significantly positive. This is in the same direction as the realized price dynamics, where market prices are more likely to deviate from $\mathrm{FV}$ in markets under CDA than in CMs.

The coefficients of the round in both regressions of BRAD (model 3 and model 5) and those of BRD (model 4 and model 6) are significantly negative. This implies the convergence of the predictions toward FV for traders with experience across rounds, which is consistent with the findings of Haruvy et al. (2007). Conversely, the coefficients of the period in both regressions of BRAD (model 3 and model 5) and those of BRD (model 4 and model 6) are significantly positive. The forecast future prices tend to get higher than FV with periods in a round. This might be caused by confusion among traders about the dynamics of FV in the experimental markets following the design of Smith et al. (1988). ${ }^{41}$ The effects of this confusion were pointed out and discussed in Kirchler et al.

\footnotetext{
${ }^{39}$ The variable of the period is $1,2, \ldots, 9$. We excluded the forecast data submitted in period 10 from these analyses. This is because in the calculation of BRAD/BRD based on $\mathrm{FV}$ for the traders with information level $1\left(F V^{1}\right), \overline{F V}_{e, r, m}$ can be 0 in period 10 when the dividend in period 10 is 0 , and because BRAD/BRD calculated based on $F V^{1}$ in period 10 cannot be defined when the dividend in period 10 is 0 .

${ }^{40}$ The planned number of forecasts submitted by traders was 7776 ( $=2$ trading institutions $\times 3$ treatments $\times 6$ markets $\times 4$ rounds $\times 9$ periods $\times 6$ traders $)$. These 7776 forecasts were divided into two equal groups and used in the regressions concerning traders with information level 0 and those with information level 1 . However The number of forecasts used in the regressions concerning traders with information level 0 was actually 36 less than planned (= 4 rounds $\times 9$ periods) because one market in CONTROL under CM was one subject short due to cancellation at the last minute.

${ }^{41}$ The FV in the experimental markets, following the design of Smith et al. (1988), declines over a round. Regarding this characteristic of the FV, Kirchler et al. (2012) reports that "the declining fundamental value process confuses subjects, as they expect the fundamental value to stay constant."
} 
Table A.2: The effects of informational asymmetry on the dynamics of forecast prices under each trading institution

\begin{tabular}{|c|c|c|c|c|}
\hline $\begin{array}{l}\text { Use prediction data } \\
\text { elicited by only traders } \\
\text { with information level }\end{array}$ & \multicolumn{2}{|c|}{0} & \multicolumn{2}{|c|}{1} \\
\hline & Model3 & Model4 & Model5 & Model6 \\
\hline Dependent value & RAD & $\mathrm{RD}$ & RAD & $\mathrm{RD}$ \\
\hline Constant & $\begin{array}{c}0.53^{* * *} \\
(12.13)\end{array}$ & $\begin{array}{c}0.37^{* * *} \\
(7.66)\end{array}$ & $\begin{array}{c}0.74^{* * *} \\
(14.95)\end{array}$ & $\begin{array}{c}0.63^{* * *} \\
(11.66)\end{array}$ \\
\hline ASYMM dummy & $\begin{array}{c}0.38^{* * *} \\
(9.98)\end{array}$ & $\begin{array}{c}0.46^{* * *} \\
(10.72)\end{array}$ & $\begin{array}{c}0.32^{* * *} \\
(7.29)\end{array}$ & $\begin{array}{c}0.40^{* * *} \\
(8.47)\end{array}$ \\
\hline CDA dummy & $\begin{array}{c}0.55^{* * *} \\
(17.44)\end{array}$ & $\begin{array}{c}0.58^{* * *} \\
(16.70)\end{array}$ & $\begin{array}{c}0.57^{* * *} \\
(15.98)\end{array}$ & $\begin{array}{c}0.68^{* * *} \\
(17.53)\end{array}$ \\
\hline Round & $\begin{array}{l}-0.23^{* * *} \\
(-20.01)\end{array}$ & $\begin{array}{l}-0.24^{* * *} \\
(-18.86)\end{array}$ & $\begin{array}{c}-0.30^{* * *} \\
(-22.94)\end{array}$ & $\begin{array}{c}-0.33^{* * *} \\
(-23.48)\end{array}$ \\
\hline Period & $\begin{array}{c}0.06^{* * *} \\
(12.85)\end{array}$ & $\begin{array}{c}0.06^{* * *} \\
(10.54)\end{array}$ & $\begin{array}{c}0.11^{* * *} \\
(19.60)\end{array}$ & $\begin{array}{c}0.10^{* * *} \\
(16.88)\end{array}$ \\
\hline $\begin{array}{c}\text { ASYMM \& } \\
\text { CDA dummy }\end{array}$ & $\begin{array}{l}-0.73^{* * *} \\
(-13.37)\end{array}$ & $\begin{array}{l}-0.84^{* * *} \\
(13.91)\end{array}$ & $\begin{array}{c}-0.86^{* * *} \\
(-13.90)\end{array}$ & $\begin{array}{l}-1.05^{* * *} \\
(-15.65)\end{array}$ \\
\hline $\begin{array}{l}\text { Adjusted } \mathrm{R}^{2} \\
\mathrm{~N}\end{array}$ & $\begin{array}{c}0.19 \\
3,852\end{array}$ & $\begin{array}{c}0.17 \\
3,852\end{array}$ & $\begin{array}{c}0.24 \\
3,888\end{array}$ & $\begin{array}{c}0.24 \\
3,888\end{array}$ \\
\hline
\end{tabular}

Notes. This table shows a summary of each of four regression analyses where the dependent variable is either BRAD or BRD. In model 3 (model 4), a regression of BRAD (BRD) using forecast data elicited from traders with information level 0 is conducted. In model 5 (model 6 ), a regression of BRAD (BRD) using forecast data elicited from traders with information level 1 is conducted. The independent variables, which are common to all four regressions, are a dummy for treatment ASYMM, a dummy for trading institution CDA, an interaction dummy between ASYMM and CDA, a variable for the round, and a variable for the period. The values of the intercepts in both model 3 and model 4 (model 5 and model 6 ) represent the effects of the baseline condition, where the informational asymmetry among traders does not exist (CONTROL and SYMM) and the trading institution is a CM. The sample size in both model 3 and model 4 is 3852, which was 36 less than planned because one market in CONTROL under CM was one subject short due to cancelation at the last minute. The sample size in both model 5 and model 6 is 3888 . All of these regression analyses employ the ordinary least squares method. The t-value of each coefficient is included in parentheses. *, $* *$, and ${ }^{* * *}$ indicate significance at the $10 \%, 5 \%$, and $1 \%$ levels, respectively. 
(2012) and other studies. ${ }^{42}$

\section{A.3 Discussion on Traders' Belief}

In real-world markets, it is hard to clarify the relationship between the trajectories of trading prices and the traders' predictions about them because we usually do not have data about how traders in real-world markets forecast future price dynamics. Conversely, this relationship can be directly investigated by eliciting subjects' forecasts in experimental markets. Positive correlations between the dynamics of realized prices and those of forecast prices have been reported by Haruvy et al. (2007), Markstädter et al. (2014), and by numerous other experimental studies. ${ }^{43}$ It is noteworthy that in our study, the positive (negative) effects of the informational asymmetry on the deviation from FV of traders' forecasts were synchronized with the expansion (reduction) of bubbles in the realized prices attributed to the informational asymmetry.

\footnotetext{
${ }^{42}$ For example, Huber and Kirchler (2012), Akiyama et al. (2013) and Cheung et al. (2014).

${ }^{43}$ Palan (2013) comprehensively surveyed the positive correlation between the realized prices and the forecast prices in studies that implemented experimental markets based on the design of Smith et al. (1988). Unlike Smith et al. (1988), Hey (1994) and Hommes et al. (2005) reported a positive correlation in the experimental markets.
} 


\section{B Appendix: Experimental instructions (in En- glish)}

We conducted the experiments in Japanese. The following section presents our experimental instructions translated from Japanese into English. Because our study's primary goal was to replicate the experimental results of Haruvy et al. (2007) and Sutter et al. (2012), we created experimental instructions that were as close as possible to theirs. 44

Note that the footnotes of following instructions were not viewed by subjects.

\section{B.1 Instructions for ASYMM markets under CDA}

In the instructions for the CONTROL (SYMM) markets, Chapter 2. Information Levels is eliminated (shortened) and the explanations of the screen interfaces are modified accordingly.

\section{B.1.1 General information}

This experiment simulates a stock market. The experimental session includes four rounds, each consisting of ten trading periods. During this process, you can sell and buy the stocks of a virtual enterprise.

Your objective in the experiment is to maximize your profits. We use a currency called MARKs. One MARK is equivalent to 0.2 yen. At the end of the experiment, your profits will be converted into yen and paid to you.

There are three ways of making a profit:

- You can realize a profit margin through buying and selling stocks

- You can earn dividends on your stock holdings

- You can accurately predict the future prices of the stocks

The first and second ways of making a profit are described in more detail in Chapter 1 . The third way is described in more detail in Chapter 3.

\section{B.1.2 Chapter 1. Market Description}

The market in which you will trade consists of six participants. The other five participants are randomly determined and do not change during the four rounds. Three of the six traders receive an initial endowment of 10 assets and working capital of 3000 MARKs, while the other three are endowed with 30 assets and working capital of 1000 MARKs. You can sell and/or buy assets in every period, and your inventory (assets and money) at the end of each period is carried over to the next trading period.

\footnotetext{
${ }^{44} \mathrm{We}$ accessed the experimental instructions used by Haruvy et al. (2007) at https://www.aeaweb.org/atypon.php?doi=10.1257/aer.97.5.1901, and that used in Sutter et al. (2012) at https://papers.ssrn.com/sol3/papers.cfm?abstract_id=1268742.
} 


\subsection{How to realize a profit margin through buying and selling stocks}

Each trader can be a buyer and a seller at the same time. Thus, buying low and selling high allows you to realize a profit margin.

\section{Example}

If you can buy the stock for 100 MARKs and sell it for 120 MARKs, you earn 20 MARKs. On the other hand, if you buy the stock for 100 MARKs and sell it for $80 \mathrm{MARKs}$, you lose 20 MARKs.

The figure below shows the screen used for trading. You can submit buy/sell orders at prices ranging from 0 MARKs to a maximum of 300 MARKs. For every bid/ask you make, you must enter the price of the assets you intend to trade. To submit a bid, you must enter the price at which you would like to buy an asset in the "Purchase Bids" box and click on the "Buying Order" button. To submit an ask, you must enter the price at which you would like to sell an asset in the "Sales Asks" box and click on the "Selling Order" button. No trade can take place until another participant accepts your bid (ask) by clicking on the "Sell" ("Buy") button. ${ }^{45}$ Note that your inventory of cash and assets cannot be less than zero.

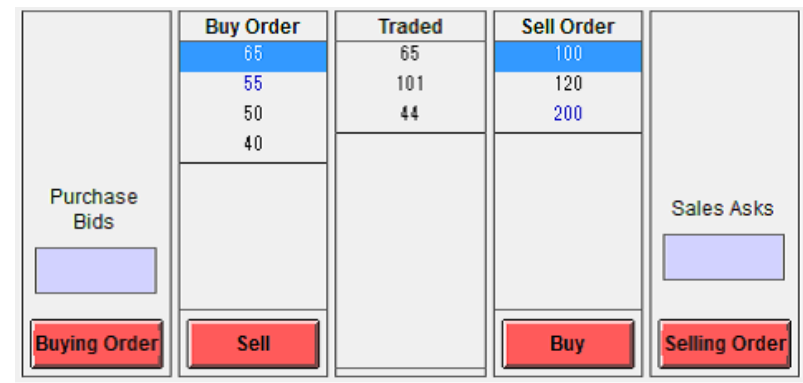

\subsection{How to earn dividends on your stock holdings}

At the end of each trading period, every asset pays a dividend. The dividend for one asset is either 0 or 20 MARKs, with equal probability. Thus, an asset's average dividend amounts to 10 MARKs in every period. After a trading period is complete, dividends for assets you hold in your inventory are added to your cash holding. Assets have a lifespan of 10 trading periods, i.e., after the final dividends are paid out at the end of period 10 in each round, the assets are worthless.

You can use the table below to help you make your decisions. The first column, labelled "Ending Period", indicates the last trading period of the round. The second column, labelled "Current Period", indicates the period during which the average holding value is being calculated. The third column shows the number

\footnotetext{
${ }^{45}$ In Sutter et al. (2012), traders were able to post limit/market orders for multiple shares of the assets. On the other hand, in our experiments under CDAs, the maximum share of the asset for each limit/market order was one. To simplify the order book's information about limit orders and transactions, the number of shares of the asset for each limit or market order was set at a maximum of one in our experiment. We confirmed that this modification did not essentially change our results because the price dynamics in our experimental markets using a CDA was similar to that in Sutter et al. (2012).
} 
of holding periods remaining from the period listed in the second column until the end of the market. The fourth column, labelled "Average Dividend Value Per Period", shows the average dividend in each period for each unit held in your inventory. The fifth column, labelled "Average Holding Value Per Unit of Inventory", shows the expected total dividend earnings (per asset) for the remainder of the round. That is, for each asset you hold in your inventory for the remainder of the round, you expect to receive the amount listed in column 5 . The number in column 5 is calculated by multiplying the numbers in columns 3 and 4.

\begin{tabular}{|c|c|c|c|c|c|c|}
\hline $\begin{array}{c}\text { Ending } \\
\text { Period }\end{array}$ & $\begin{array}{c}\text { Current } \\
\text { Period }\end{array}$ & $\begin{array}{c}\text { Number of } \\
\text { Holding } \\
\text { Periods }\end{array}$ & $\times$ & $\begin{array}{c}\text { Average } \\
\text { Dividend Value } \\
\text { Per Period }\end{array}$ & $=$ & $\begin{array}{c}\text { Average Holding } \\
\text { Value Per Unit } \\
\text { of Inventory }\end{array}$ \\
\hline 10 & 1 & 10 & & 10 & & 100 \\
\hline 10 & 2 & 9 & & 10 & & 90 \\
\hline 10 & 3 & 8 & & 10 & & 80 \\
\hline 10 & 4 & 7 & & 10 & & 60 \\
\hline 10 & 5 & 6 & & 10 & & 40 \\
\hline 10 & 6 & 5 & & 10 & & 30 \\
\hline 10 & 7 & 4 & & 10 & & 20 \\
\hline 10 & 8 & 3 & & 10 & & 10 \\
\hline 10 & 9 & 2 & & 10 & & \\
\hline 10 & 10 & 1 & & 10 & & \\
\hline
\end{tabular}

\section{Example}

Suppose there are four periods remaining in a round. Since the dividend on a unit of asset has a $50 \%$ chance of being 0 MARKs and a $50 \%$ chance of being 20 MARKs, the expected dividend is, on average, expected to be 10 MARKs per period for each asset. If you hold one asset for four periods, the total dividend paid on the unit over the four periods is expected to be $4 \times 10=40$ MARKs.

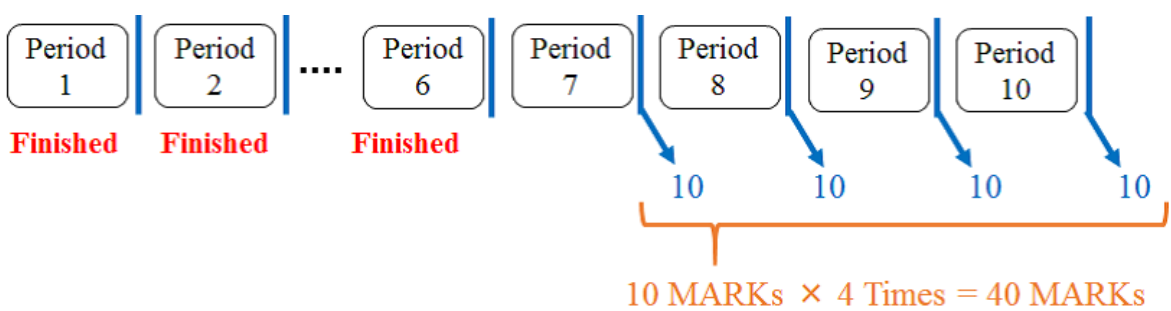

\subsection{After first market}

After the round is complete (i.e., after 10 trading periods), the round is replicated three more times. Note that once again, the actual dividends will be randomly chosen by the computer (with an equal probability of either 0 or 20 MARKs). Regardless of the profit you earned in the first round, you will once again be endowed with an inventory of 10 (30) assets and 3000 (1000) MARKs 
at the beginning of rounds two, three, and four. Your total profit will be calculated by adding up your earnings and prediction bonuses from all four rounds at the end of the experiment. Prediction bonuses are explained in Chapter 3.

\section{B.1.3 Chapter 2. Information Levels}

The present market is characterized by different information levels $(0,1)$ of traders. At the beginning of the experiment, you will be randomly assigned to one of these levels.

Three of the six participants (with information level 0) receive no information about dividend realization, i.e., they have no information about the actual dividend payment in the current period. They just know that the dividend in every period will amount to either 0 or 20 MARKs. At the end of a period, all participants (including those with information level 0) are told about the actual dividend payment in the just-terminated trading period.

The other three participants in the market are classified as traders with information level 1 , and have a prediction horizon of one period in advance, i.e., they possess information about the actual dividend payment (0 or 20 MARKs) for the current period before trading commences.

\section{Example}

If the actual dividend payment for period 3 is 20 MARKs, the traders with information level 1 know that the dividend will be 20 MARKs before trading in period 3 commences, while the traders with information level 0 only learn this at the end of period 3 .

The following figure is the screenshot showing your information level. This is shown at the beginning of each market.

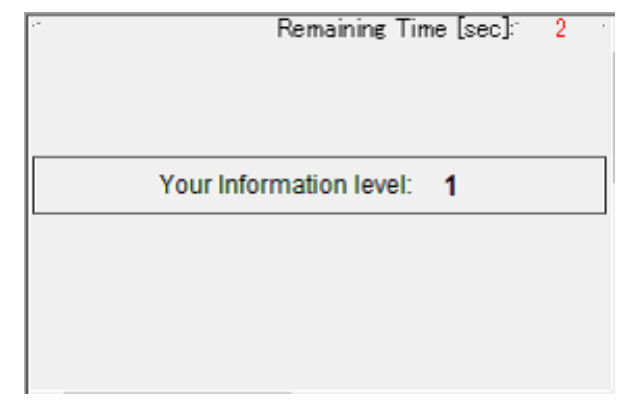

\section{B.1.4 Chapter 3. How to make a profit by accurately predicting the future prices of stocks}

You can make a profit not only by achieving a margin between buying and selling prices and through dividends, but also by accurately predicting the future prices of stocks (prediction bonus). Before each period begins, you will be given two minutes to predict the average trading prices in all the remaining periods. ${ }^{46}$

\footnotetext{
${ }^{46}$ In "Price History" area (lower left area), the highest bid price in a given period was recorded if no transactions occurred.
} 


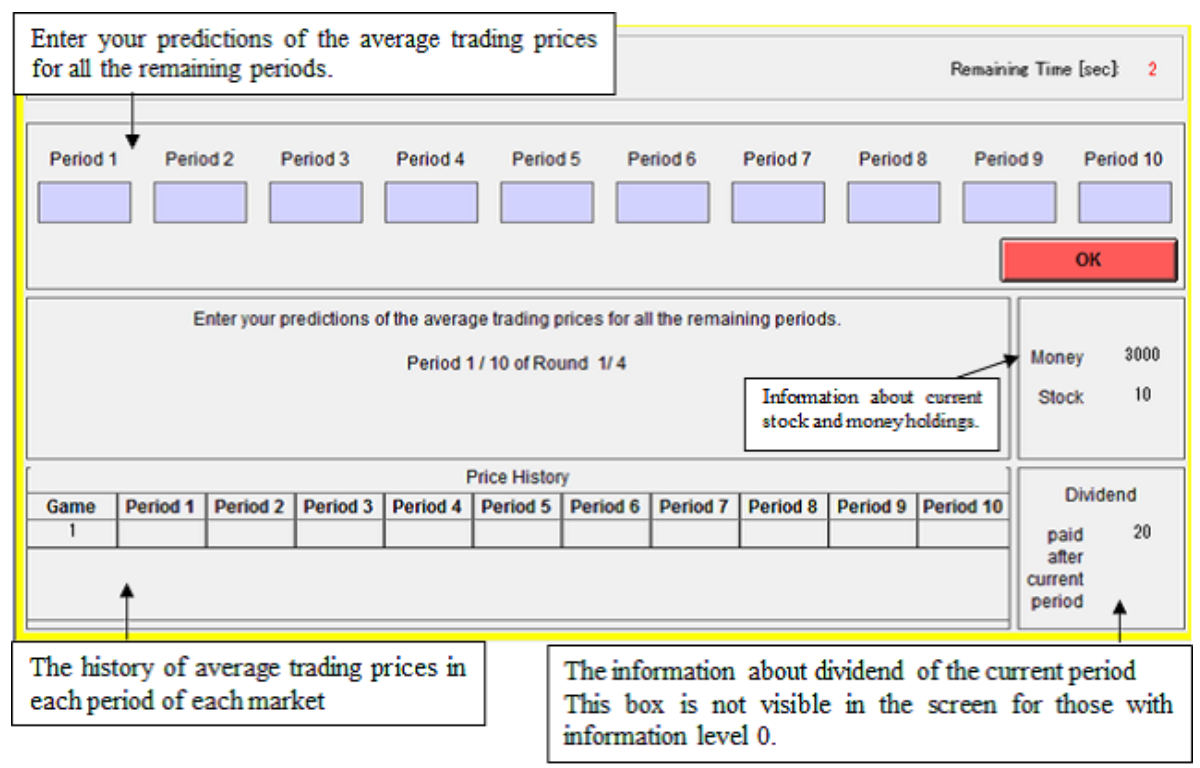

The computer will keep a record of the number of accurate predictions (that is, your predicted prices that were between $90 \%$ and $110 \%$ of the realized average trading price for each period). At the end of each round, you will be offered a prediction bonus based on the number of accurate predictions you made according to the following formula: (your final cash balance) $\times 0.5 \% \times$ (the number of accurate predictions). The maximum bonus payable is $0.5 \% \times 55=27.5 \%$. Please be aware that because your final cash balance depends on both profits from trading and dividends, the prediction bonus decreases as profits from trading and dividends decrease.

\section{B.1.5 Chapter 4. Calculating Your Earnings}

Your earnings for a period are given by the actual dividends received at the end of the period plus revenue from assets sold minus expenditure on assets purchased.

YOUR EARNINGS FOR A PERIOD =

DIVIDEND PER UNIT $\times$ NUMBER OF UNITS IN INVENTORY $($ AT THE END OF THE PERIOD) + REVENUES - EXPENDITURES (ACCRUING IN THE COURSE OF TRADING).

If you buy assets, your cash holding is diminished by the associated expenditure (price $\times$ volume). Conversely, if you sell assets, your cash holding will be increased by the associated revenue (price $\times$ volume). Your total profit in the market results from the initial cash endowment (1000 or $3000 \mathrm{MU})$, plus the sum of earnings acquired in all 10 trading periods, plus Prediction Bonus in the market.

YOUR TOTAL EARNINGS IN THE MARKET = INITIAL CASH ENDOWMENT + 
EARNINGS FOR PERIOD $1+$ EARNINGS FOR PERIOD $2+$ EARNINGS FOR PERIOD $3+$ EARNINGS FOR PERIOD $4+$ EARNINGS FOR PERIOD $5+$ EARNINGS FOR PERIOD $6+$ EARNINGS FOR PERIOD $7+$ EARNINGS FOR PERIOD $8+$ EARNINGS FOR PERIOD $9+$ EARNINGS FOR PERIOD $10+$ Prediction Bonus in the market

At the end of each round, assets have a value of zero. Therefore, your total profit for the experiment is the sum of your profits from all four (independent) rounds. This profit is converted into yen at the exchange rate of 100 MARKs $=20$ yen. You will also receive a participation fee of 500 yen.

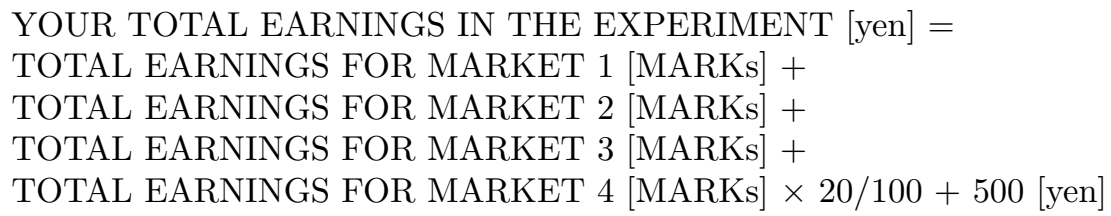

\section{B.1.6 Chapter 5. Trading Screen}

The following figure illustrates the trading procedure. Each trading period automatically terminates after two minutes. You can submit orders and trade stocks in the ${ }^{*}$ area. Descriptions of how to submit orders and trade stocks in the ${ }^{*}$ area are provided on the next page. 


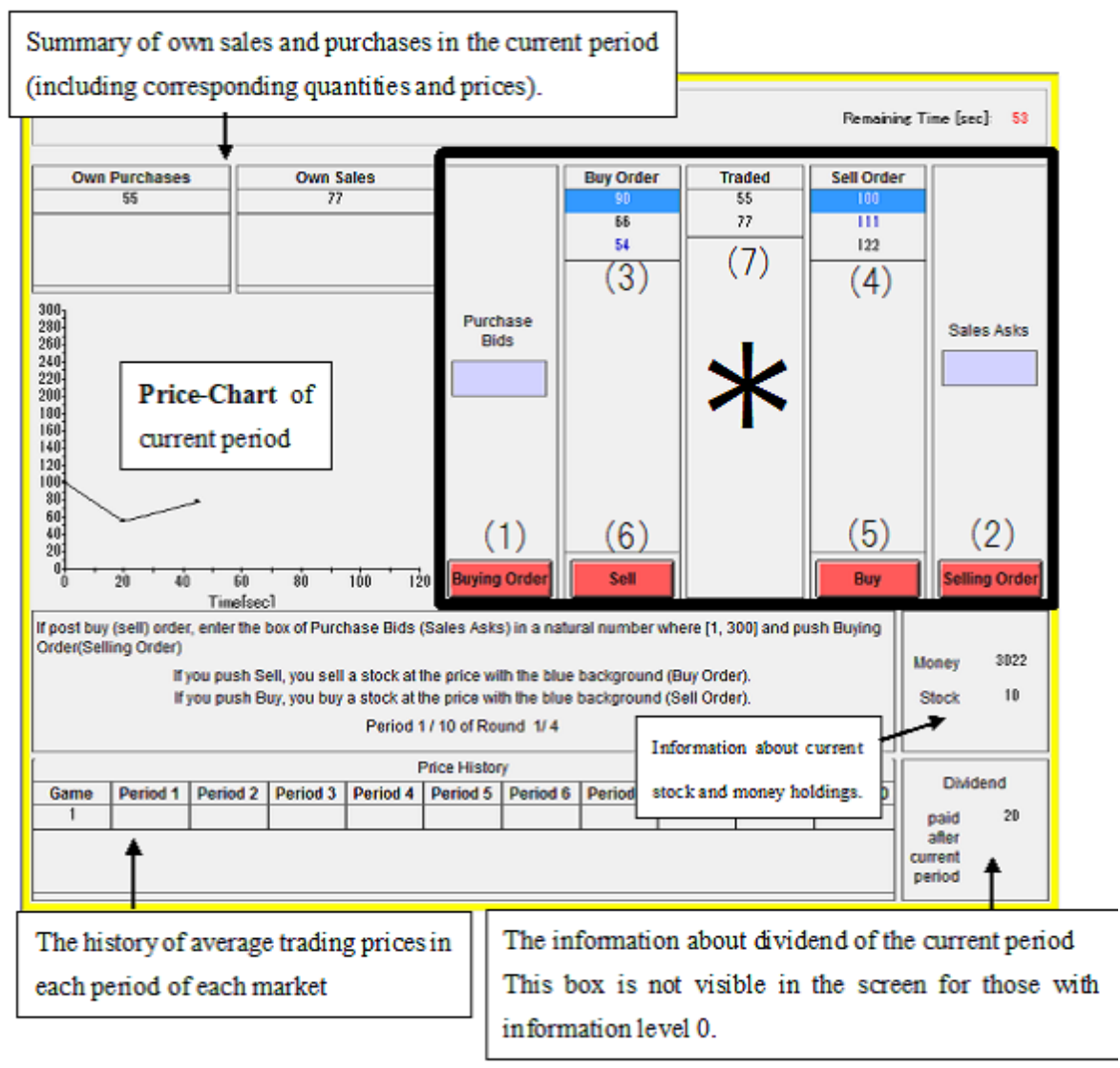

\section{How to submit orders and trade stocks in the * area}

- (1) Buying Order: you click on this button to enter a bid price. A trade does not take place until another participant accepts your offer.

- (2)Selling Order: you click on this button to enter an ask price. A trade does not take place until another participant accepts your offer.

- (3)Buy Order: this shows buying orders from all traders, with your own bids shown in blue and those of the other traders in black. The offer with a blue background is always the best, i.e., it yields the highest revenue for the seller.

- (4)Selling Order: this shows selling orders from all traders, with your own asks shown in blue and those of the other traders shown in black. The offer with a blue background is always the best, i.e., it is the cheapest option for the buyer.

- (5)Buy: You click on this button to buy a stock at the price shown against a blue background.

- (6) Sell: You click on this button to sell a stock at the price shown against a blue background.

- (7)Traded: this shows all transactions in the current period in chronological order. 


\section{B.1.7 Chapter 6. History Screen}

After every trading period, this screen provides you with vital information for 30 seconds. In particular, the box containing the \# symbol shows important information about your predictions concerning the current period. The average actual trading price in the current period is shown on the first line. The second line shows the number of predicted prices that were in the range between $90 \%$ and $110 \%$ of the average actual trading price.

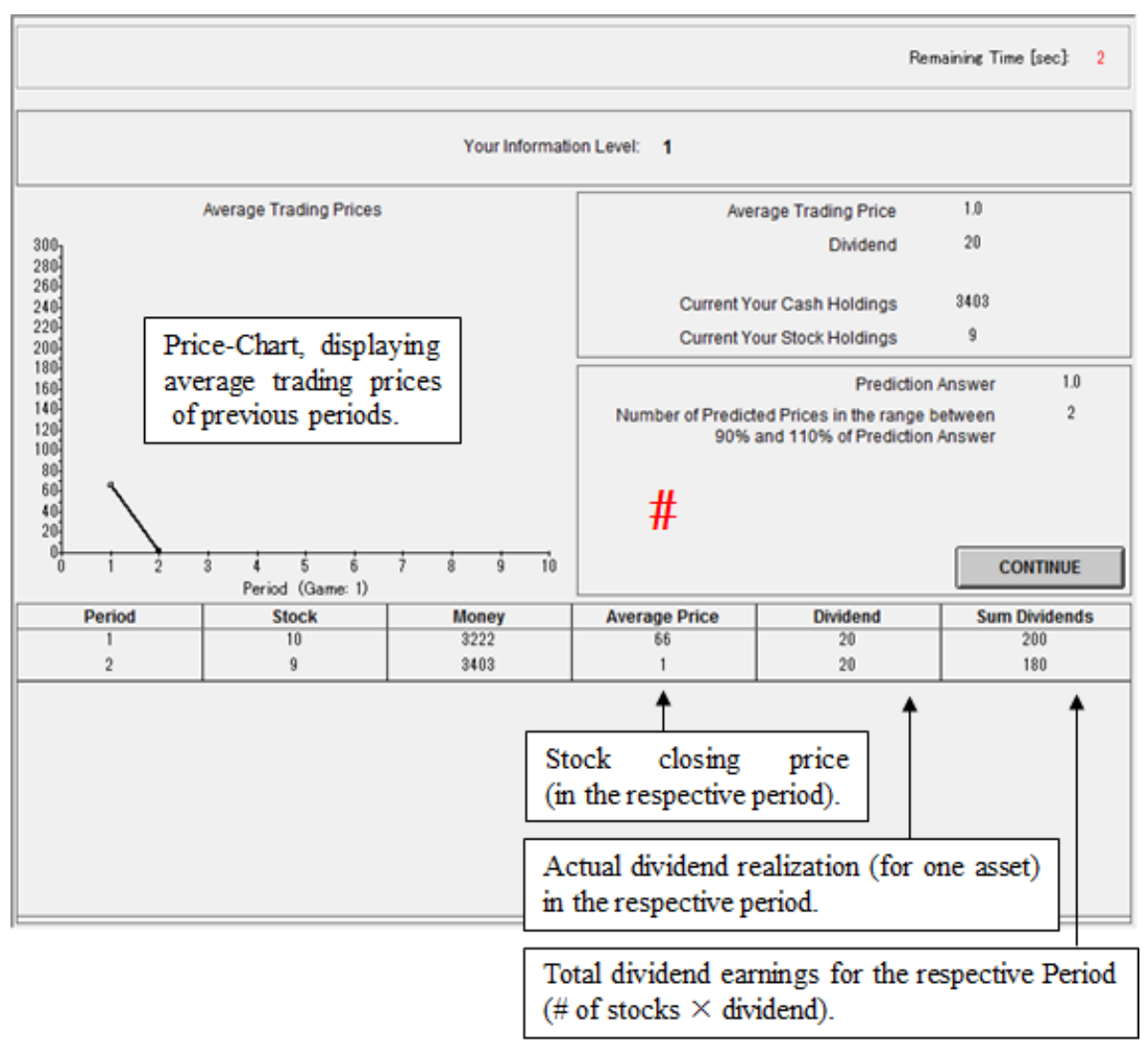




\section{B.2 Instructions for ASYMM markets under CM}

In the instructions for the CONTROL (SYMM) markets, Chapter 2. Information Levels is eliminated (shortened) and the explanations of the screen interfaces are modified accordingly.

\section{B.2.1 General information}

Analogue to the instructions in $C D A$ ( B.1).

\section{B.2.2 Chapter 1. Market Description}

Analogue to the instructions in $C D A$ ( B.1).

1.1 How to realize a profit margin through buying and selling stocks Each trader can be a buyer and a seller at the same time. Thus, buying low and selling high allows you to realize a profit margin.

\section{Example}

If you can buy the stock for 100 MARKs and sell it for 120 MARKs, you earn 20 MARKs. On the other hand, if you buy the stock for 100 MARKs and sell it for 80 MARKs, you lose 20 MARKs.

The following figure shows part of the screen used for trading. At the beginning of each trading period, if you wish to purchase assets, you can place a buy order. Your buy order indicates the number of assets you would like to buy and the highest price that you are willing to pay. Similarly, if you wish to sell assets, you can place a sell order. Your sell order indicates the number of assets you are offering to sell and the lowest price that you are willing to accept. The price at which you offer to buy must be less than or equal to the price at which you offer to sell. The price you specify in your order is a per-unit price. Note that your cash and asset inventory cannot be less than zero.

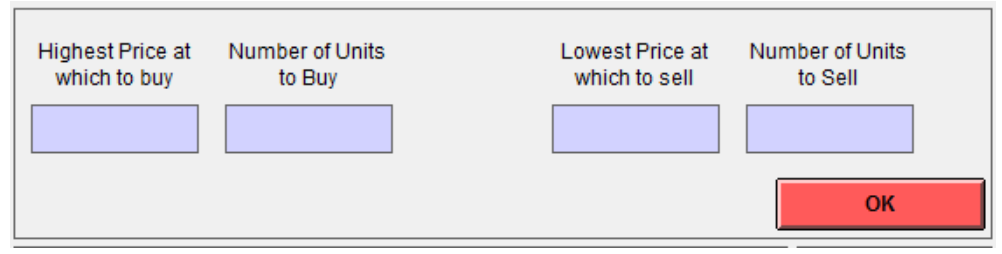

The computer program will organize the buy and sell orders and use them to determine the market price at which units are bought and sold. All transactions in a given period occur at the same market price. This will generally be the price at which the number of assets with sell order prices at or below it is equal to the number of assets with buy order prices at or above it. Traders who submit buy orders at prices above or equal to the market price make purchases, and those who submit sell orders at prices below or equal to the market price make 
sales. ${ }^{47}$ The following examples show how the market price is determined.

Consider the following buy/sell orders placed by four traders:

- Trader A: One sell order, which can be executed at 10 MARKs or higher

- Trader B: Two sell orders, which can be executed at 40 MARKs or higher

- Trader C: One buy order, which can be executed at 60 MARKs or lower

- Trader D: One buy order, which can be executed at 20 MARKs or lower

A graph summarizing these orders is shown below.

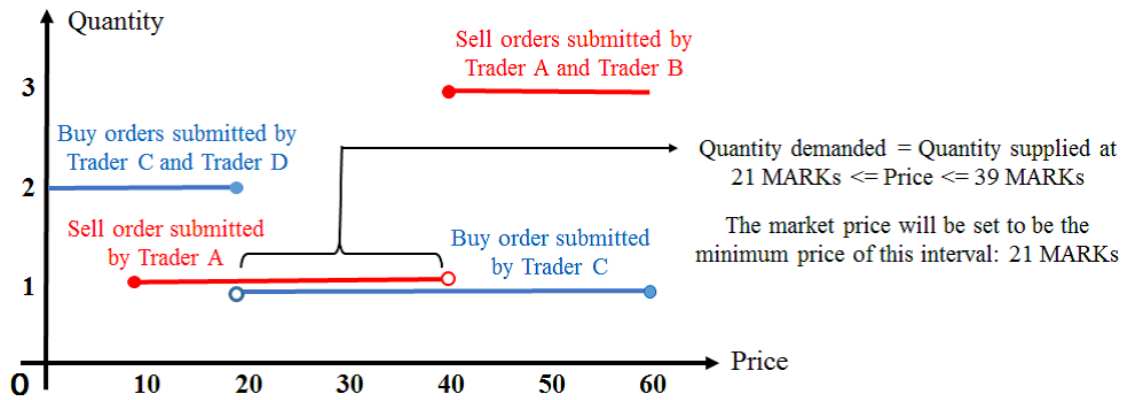

A seller is willing to sell at either the price requested or a higher price. A buyer is willing to buy at either the price offered or a lower price. As shown above, there is only one stock offered at 10 MARKs or higher. If the price rises to 40 MARKs, the number of stocks offered increases to three. Conversely, only one stock is demanded at 60 MARKs or lower. If the price falls to 20 MARKs, the number of stocks demanded increases to two. Therefore, the quantity demanded is equal to the quantity supplied at prices between 21 MARKs and 39 MARKs. The market price is set to the minimum price in this range, i.e., 21 MARKs.

Consider the following buy/sell orders placed by five traders:

- Trader A: One sell order, which can be executed at 10 MARKs or higher - Trader B: One sell order, which can be executed at 30 MARKs or higher - Trader C: One sell order, which can be executed at 30 MARKs or higher - Trader D: One buy order, which can be executed at 60 MARKs or lower - Trader E: One buy order, which can be executed at 30 MARKs or lower

A graph summarizing these orders is shown below.

\footnotetext{
${ }^{47}$ When there were excess bids (asks) at a particular price, the computer excluded the excess bids (asks) in ascending (descending) order of prices until demand equaled supply. If the highest bid price was lower than the lowest ask price (i.e., the demand curve was below the supply curve), no transactions occurred and the traders were informed of the highest bid price.
} 


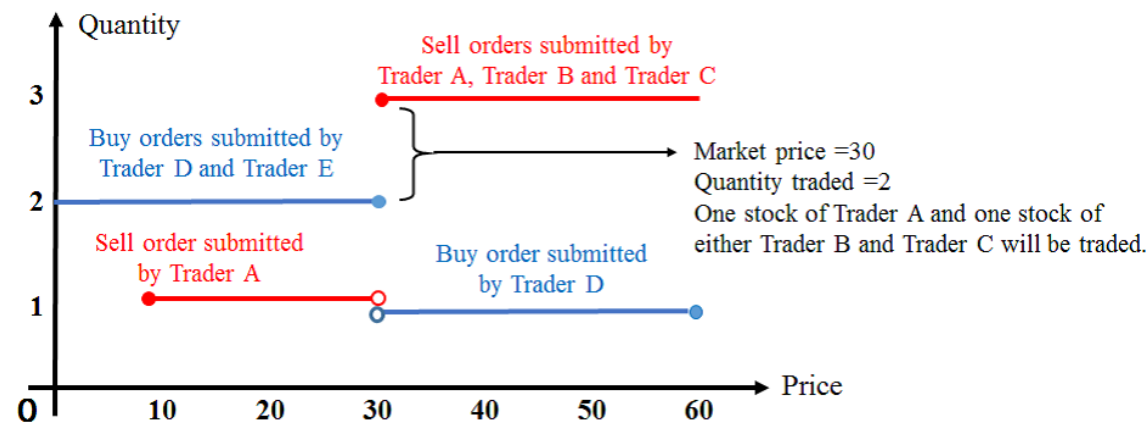

As shown above, only one stock is offered at 10 MARKs or higher, as in the previous example. If the price rises to $30 \mathrm{MARKs}$, the number of stocks that are offered increases to three. However, there is only one stock demanded at 60 MARKs or lower. If the price falls to 30 MARKs, the quantity demanded increases to two. As a result, two transactions can be completed at 30 MARKs. In this case, the market price is set to 30 MARKs. The orders that will be fulfilled are determined as follows. Priority is given to Trader A, because he/she requested a price less than the market price. In addition, the order of either Trader B or Trader $\mathrm{C}$ will be fulfilled, the choice being determined randomly by the computer.

\subsection{How to earn dividends on your stock holdings}

Analogue to the instructions in CDA (B.1).

\subsection{After first market}

Analogue to the instructions in CDA (B.1).

\section{B.2.3 Chapter 2. Information Levels}

Analogue to the instructions in $C D A$ ( B.1).

\section{B.2.4 Chapter 3. How to make a profit by accurately predicting the future prices of stocks}

Analogue to the instructions in $C D A$ ( B.1).

\section{B.2.5 Chapter 4. Calculating Your Earnings}

Analogue to the instructions in CDA (B.1). 


\section{B.2.6 Chapter 5. Trading Screen}

The following figure illustrates the trading procedure. ${ }^{48}$ At the beginning of each trading period, you have 60 seconds to submit a buy/sell order. ${ }^{49}$

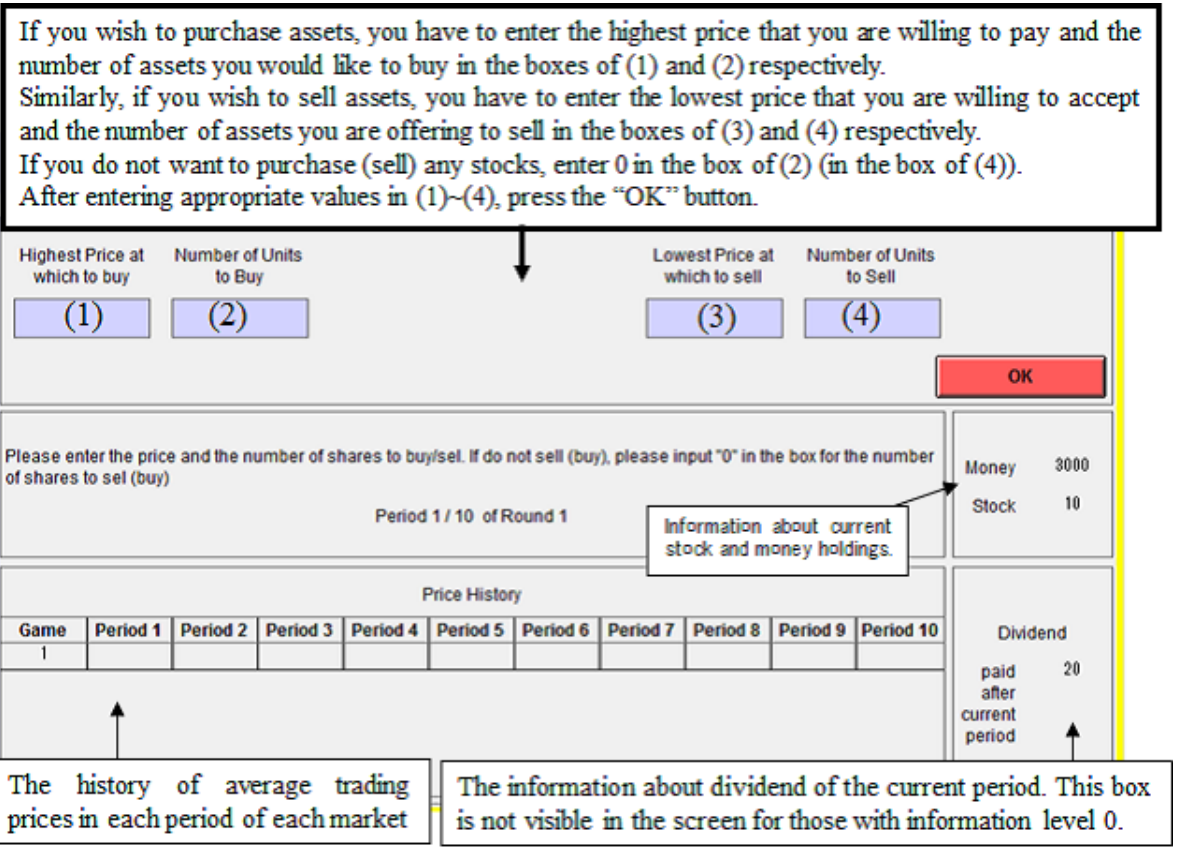

The most important points in relation to the buying and selling of stocks are summarized below.

- You can simultaneously place buy and sell orders, or you can place only a buy or a sell order. You can also decide not to place any orders at all.

- If you do not want to submit a buy order, enter 0 as the quantity to buy. If you do not want to submit a sell order, enter 0 as the quantity to sell.

- The screen displays an error message if any of the following conditions are violated:

1. The quantity you wish to sell must be less than or equal to the number of units you hold.

2. The maximum purchase price multiplied by the quantity you wish to buy must be less than or equal to your cash holding at the time.

\footnotetext{
${ }^{48}$ The middle and lower areas of this screen show the information commonly used in both CDAs and CMs. Therefore, we implemented these areas as similar to those of CDAs' screens as possible.

${ }^{49}$ To equalize the total amount of time spent on experiments employing CMs and those employing CDAs, the time limit for the CM trading screen is set to 60 seconds $(120$ seconds under CDAs). This is because the calculations in the experiments employing CMs take longer than those in the experiments employing CDAs. Note that, in CMs, even if the time has expired in a period, none of the traders leave the history screen until all the traders have submitted an order. In many cases, all the traders submit their orders within 60 seconds.
} 
3. If you simultaneously place buy and sell orders, the maximum price at which you are prepared to buy must be less than or equal to the minimum selling price you are prepared to accept. ${ }^{50}$

\section{B.2.7 Chapter 6. History Screen}

After every trading period, this screen provides you with vital information for 30 seconds. In particular, the box containing the \# symbol shows important information concerning the current period. The first line shows the market price, as explained previously. The second and third lines show the number of stocks you have purchased and sold, respectively, in the current period. The fourth line shows the actual dividend payment (0 or 20 MARKs) for the current period. The fifth and sixth lines show your current cash and stock holdings, respectively. The seventh line shows the number of predicted prices that were in the range between $90 \%$ and $110 \%$ of the market price.

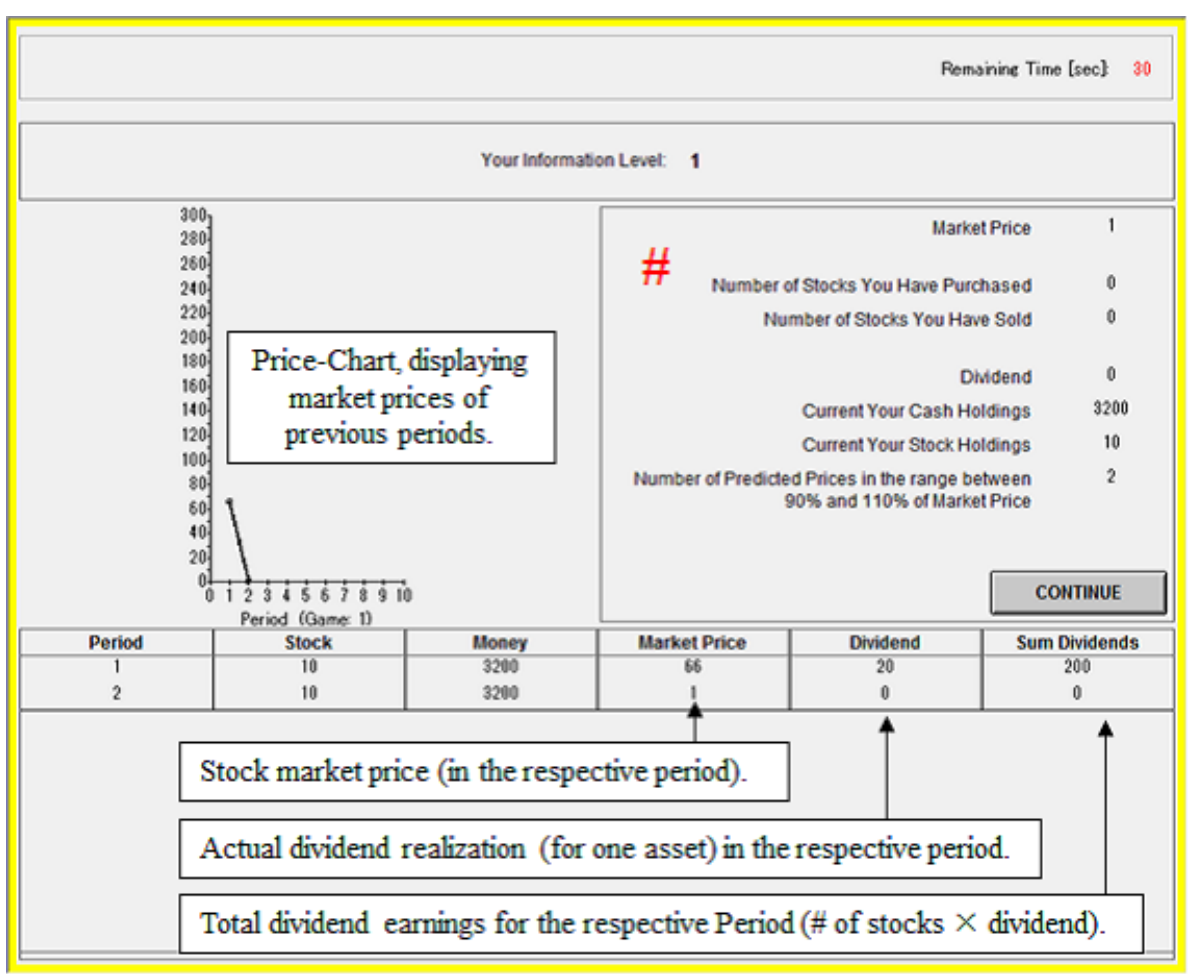

\footnotetext{
${ }^{50}$ This constraint is typical of experimental studies employing CMs. Many experimental studies using CMs impose a similar constraint on orders (Boening et al. 1993, Haruvy et al. 2007, Akiyama et al. 2013, Akiyama et al. 2014). This is because buying and selling at prices where the purchase price is higher than the selling price results in the loss of cash, and thus is nonsense.
} 


\section{Appendix: Predetermining Dividends and Re- alized Values of Those}

\section{C.1 Predetermining Dividends}

We predetermined the dividend ( 0 or $20 \mathrm{MARKs}$ ) following the procedure used in Sutter et al. (2012).

Before the experiments commenced, we created 40 dividends $(10$ periods $\times$ 4 rounds), which we named the first array. The "mirroring" process converted the first array into the second array: when the n-th element of the first array was 0 (20) MARKs, the n-th element of the second array was 20 (0) MARKs. In this way, we created six arrays (three pairs of first array and second array). There are six kinds of settings (= three treatments $\times$ two trading institutions) in our study. We conducted six markets for each kind of setting. The dividend stream of the six markets in each of six kinds of settings followed the above six array.

This procedure was designed "to not confound possible differences across treatments" and trading institutions "by different realizations of the dividends" (Sutter et al., 2012) using three treatments and two trading institutions.

\section{C.2 Dividends Used in This Study}

The following Tables C.1 - C.4 shows all values in the six arrays of 40 realized dividends (10 periods $\times 4$ rounds) that were applied in our experimental markets. In Tables C.1 - C.4, Array 1, 3 and 5 are classified as first array. Array 2, 4 and 6 are the second array corresponding to Array 1, 3 and 5 respectively.

Table C.1: Actual dividends across 10 periods of round 1 in the 6 markets of each treatment

\begin{tabular}{ccccccc}
\hline Period & Array 1 & Array 2 & Array 3 & Array 4 & Array 5 & Array 6 \\
\hline 1 & 20 & 0 & 20 & 0 & 0 & 20 \\
2 & 20 & 0 & 0 & 20 & 20 & 0 \\
3 & 20 & 0 & 20 & 0 & 20 & 0 \\
4 & 0 & 20 & 20 & 0 & 20 & 0 \\
5 & 0 & 20 & 20 & 0 & 0 & 20 \\
6 & 0 & 20 & 0 & 20 & 20 & 0 \\
7 & 0 & 20 & 20 & 0 & 20 & 0 \\
8 & 20 & 0 & 0 & 20 & 0 & 20 \\
9 & 20 & 0 & 20 & 0 & 0 & 20 \\
10 & 0 & 20 & 0 & 20 & 20 & 0 \\
\hline
\end{tabular}


Table C.2: Actual dividends across 10 periods of round 2 in the 6 markets of each treatment

\begin{tabular}{|c|c|c|c|c|c|c|}
\hline Period & Array 1 & Array 2 & Array 3 & Array 4 & Array 5 & Array 6 \\
\hline 11 & 0 & 20 & 0 & 20 & 20 & 0 \\
\hline 12 & 20 & 0 & 0 & 20 & 0 & 20 \\
\hline 13 & 20 & 0 & 0 & 20 & 20 & 0 \\
\hline 14 & 20 & 0 & 0 & 20 & 0 & 20 \\
\hline 15 & 0 & 20 & 0 & 20 & 0 & 20 \\
\hline 16 & 0 & 20 & 20 & 0 & 0 & 20 \\
\hline 17 & 20 & 0 & 20 & 0 & 0 & 20 \\
\hline 18 & 20 & 0 & 20 & 0 & 20 & 0 \\
\hline 19 & 0 & 20 & 0 & 20 & 20 & 0 \\
\hline 20 & 20 & 0 & 0 & 20 & 20 & 0 \\
\hline
\end{tabular}

Table C.3: Actual dividends across 10 periods of round 3 in the 6 markets of each treatment

\begin{tabular}{|c|c|c|c|c|c|c|}
\hline Period & Array 1 & Array 2 & Array 3 & Array 4 & Array 5 & Array 6 \\
\hline 21 & 20 & 0 & 20 & 0 & 0 & 20 \\
\hline 22 & 20 & 0 & 20 & 0 & 20 & 0 \\
\hline 23 & 20 & 0 & 0 & 20 & 20 & 0 \\
\hline 24 & 20 & 0 & 20 & 0 & 0 & 20 \\
\hline 25 & 20 & 0 & 0 & 20 & 0 & 20 \\
\hline 26 & 20 & 0 & 20 & 0 & 0 & 20 \\
\hline 27 & 0 & 20 & 20 & 0 & 20 & 0 \\
\hline 28 & 20 & 0 & 0 & 20 & 20 & 0 \\
\hline 29 & 0 & 20 & 20 & 0 & 20 & 0 \\
\hline 30 & 0 & 20 & 0 & 20 & 20 & 0 \\
\hline
\end{tabular}

Table C.4: Actual dividends across 10 periods of round 4 in the 6 markets of each treatment

\begin{tabular}{ccccccc}
\hline Period & Array & Array 2 & Array 3 & Array 4 & Array 5 & Array 6 \\
\hline 31 & 20 & 0 & 0 & 20 & 0 & 20 \\
32 & 0 & 20 & 0 & 20 & 20 & 0 \\
33 & 0 & 20 & 0 & 20 & 20 & 0 \\
34 & 20 & 0 & 20 & 0 & 20 & 0 \\
35 & 0 & 20 & 20 & 0 & 20 & 0 \\
36 & 20 & 0 & 20 & 0 & 20 & 0 \\
37 & 0 & 20 & 0 & 20 & 0 & 20 \\
38 & 20 & 0 & 0 & 20 & 0 & 20 \\
39 & 0 & 20 & 20 & 0 & 0 & 20 \\
40 & 20 & 0 & 0 & 20 & 0 & 20 \\
\hline
\end{tabular}




\section{Appendix: Realized Price Analyses where RAD and RD based on $F V^{0}$ were used in ASYMM}

We conducted regression analyses where the dependent variables were RAD (model 7) and RD (model 8), in addition to the analyses reported in Table 1, where RAD and RD in the ASYMM markets were calculated based on the asset's fundamental value (FV) for the traders with information level $1\left(F V^{1}\right)$. In these analyses, the RAD and RD in the ASYMM markets were calculated based on the FV for traders with information level $0\left(F V^{0}\right)$, and were used as the dependent variables. The independent variables and sample size for these analyses are identical to those in the analyses reported in Table 1 . These regression analyses also employed the ordinary least squares method. All coefficients displayed the qualitatively same values as those reported in Table 1 . Thus, the results reported in Table 1 are robust to the difference between values of RAD/RD in ASYMM markets based on $F V^{0}$ and those based on $F V^{1}$.

Table D.1: The effects of informational asymmetry on bubbles under each of trading institutions (using RAD/RD of the ASYMM markets based on $F V^{0}$ )

\begin{tabular}{lcc}
\hline & Model 7 & Model 8 \\
\hline Dependent value & RAD & RD \\
\hline Constant & $0.33^{* * *}$ & $0.16^{* *}$ \\
& $(6.21)$ & $(2.27)$ \\
ASYMM dummy & $0.10^{*}$ & $0.14^{*}$ \\
& $(1.69)$ & $(2.00)$ \\
CDA dummy & $0.14^{* * *}$ & $0.23^{* * *}$ \\
& $(3.09)$ & $(3.92)$ \\
Round & $-0.06^{* * *}$ & $-0.08^{* * *}$ \\
& $(-3.62)$ & $(-3.88)$ \\
ASYMM \& CDA dummy & $-0.18^{* *}$ & $-0.36^{* * *}$ \\
& $(-2.19)$ & $(-3.53)$ \\
Adjusted R & & 0.12 \\
N & 0.12 & 0.14 \\
\hline
\end{tabular}

Notes. This table shows a summary of regression analyses where the dependent variables are RAD (model 7) and RD (model 8). In these analyses, RAD and RD in the ASYMM markets are based on FV0 (the FV for traders with information level 0). The independent variables in both of these regressions are a dummy for treatment ASYMM, a dummy for trading institution CDA, an interaction dummy between ASYMM and CDA, and a variable for the round. The values of the intercepts in both of these models represent the effects of the baseline condition, where the informational asymmetry among traders does not exist (CONTROL and SYMM) and the trading institution is a CM. The sample size for the regressions of RAD and RD is 144 ( $=2$ trading institutions $\times 3$ treatments $\times 6$ markets $\times 4$ rounds). These regression analyses employ the ordinary least squares method. The t-values are included in parentheses. *, **, and $* * *$ indicate significance at the $10 \%, 5 \%$, and $1 \%$ levels, respectively. 


\section{E Appendix: Traders' belief dynamics using 3D bar charts in the same way as Haruvy et al. (2007)}

Figures E.1 - E.8 show the dynamics of the average forecast prices submitted by traders with each information level (0 or 1$)$ in the markets under various treatments (CONTROL, SYMM, or ASYMM) under each trading institution (open-book continuous double auction or closed-book call market). In each figure, the dynamics of the forecast prices in rounds 1 to 4 are shown separately using a three-dimensional bar chart, as in Haruvy et al. (2007). In each chart, the abscissa axis represents the period for which the subjects predicted the market price, the ordinate axis represents the period during which their forecasts were elicited, and the applicate axis represents the average of the forecast prices.

Figure E.1: The CONTROL markets under CDA

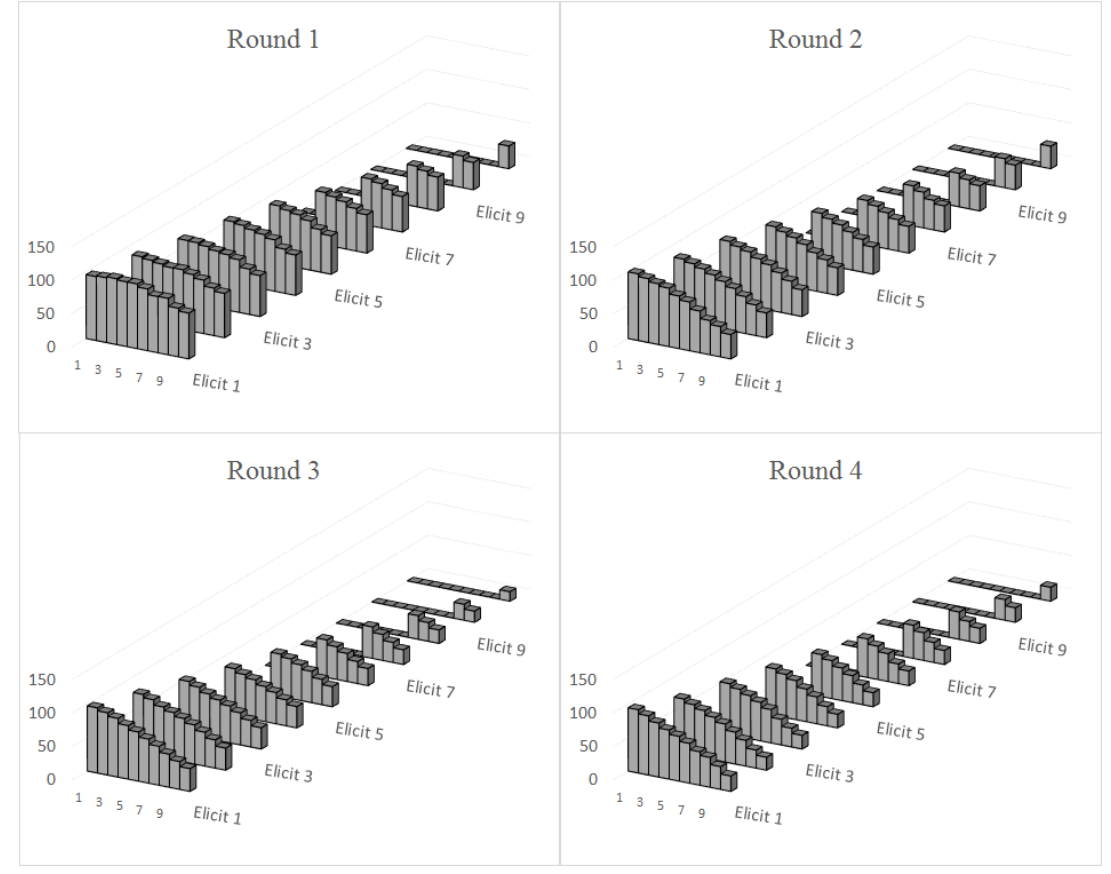


Figure E.2: The SYMM market under CDA
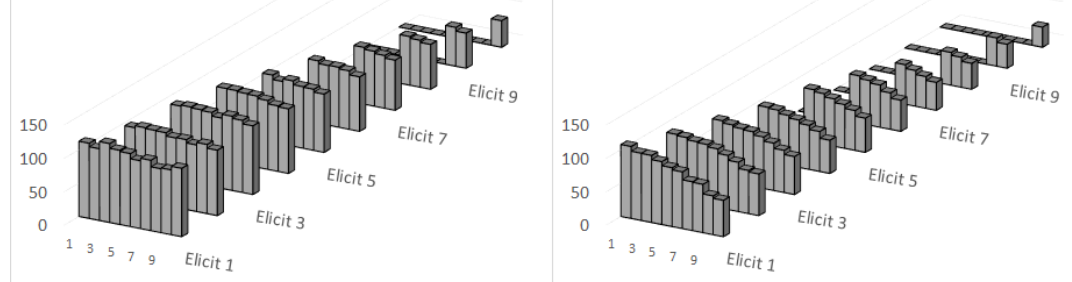

Round 3

$$
\text { Round } 4
$$
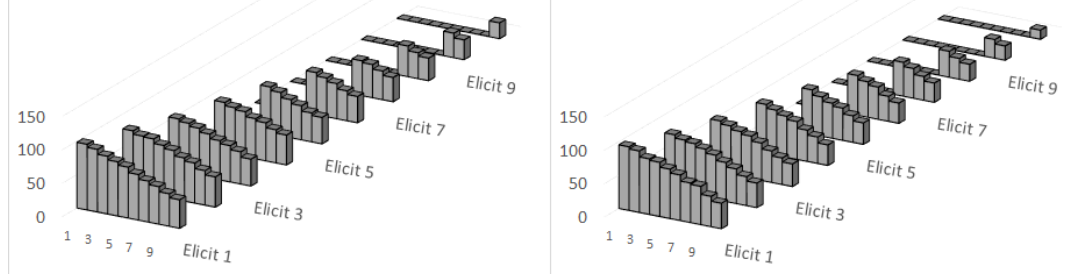

Figure E.3: The ASYMM market under CDA (information level 0)

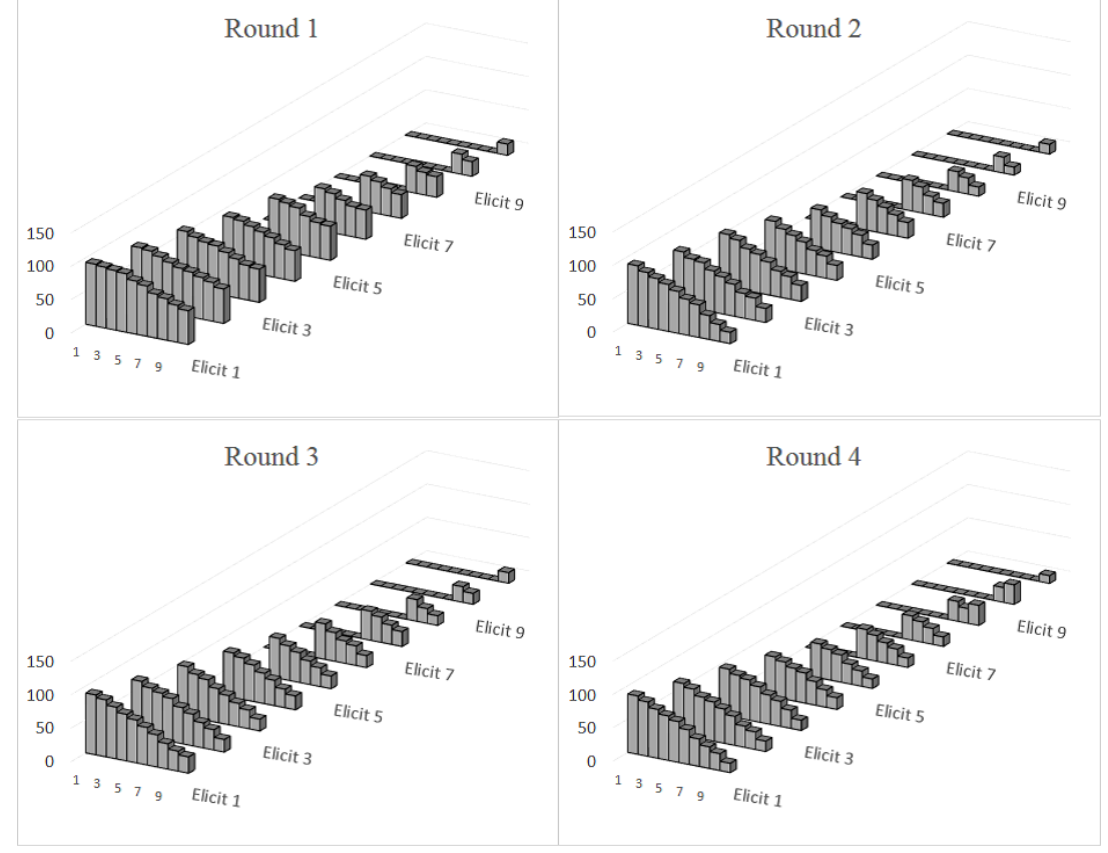


Figure E.4: The ASYMM market under CDA (information level 1)

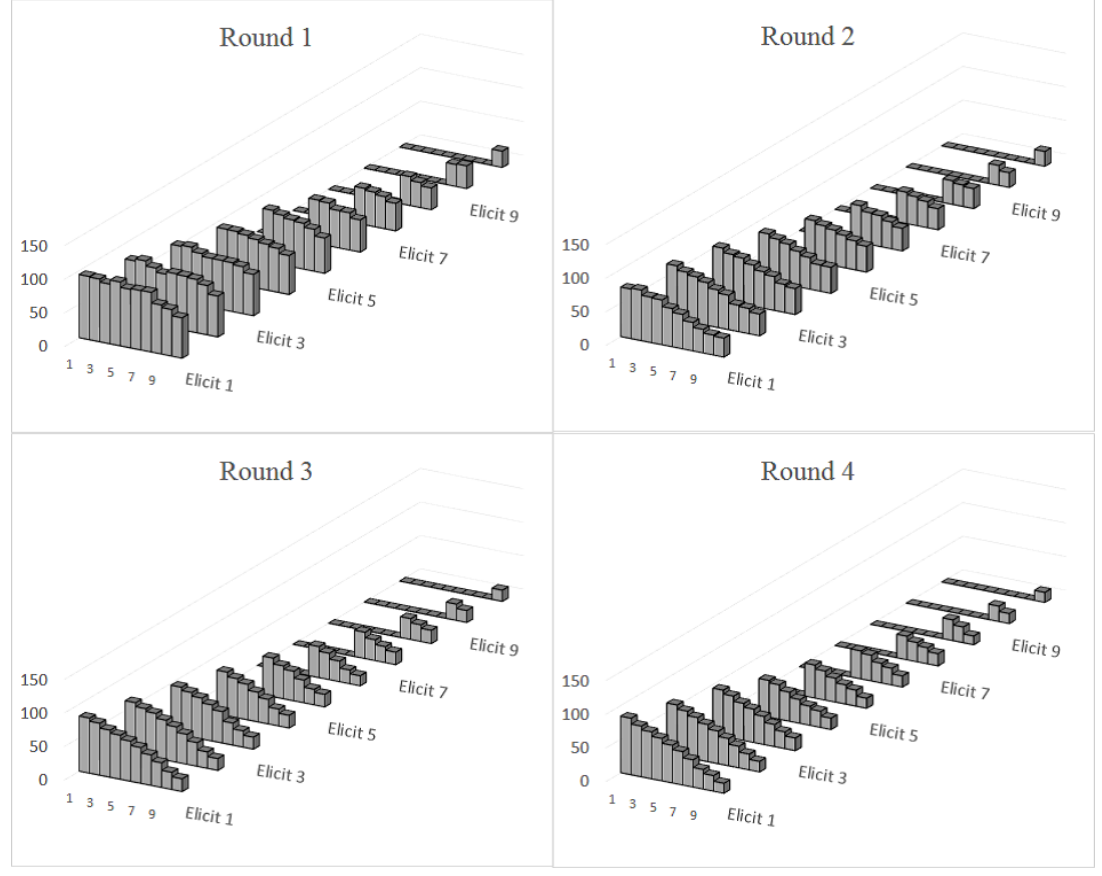

Figure E.5: The CONTROL market under CM

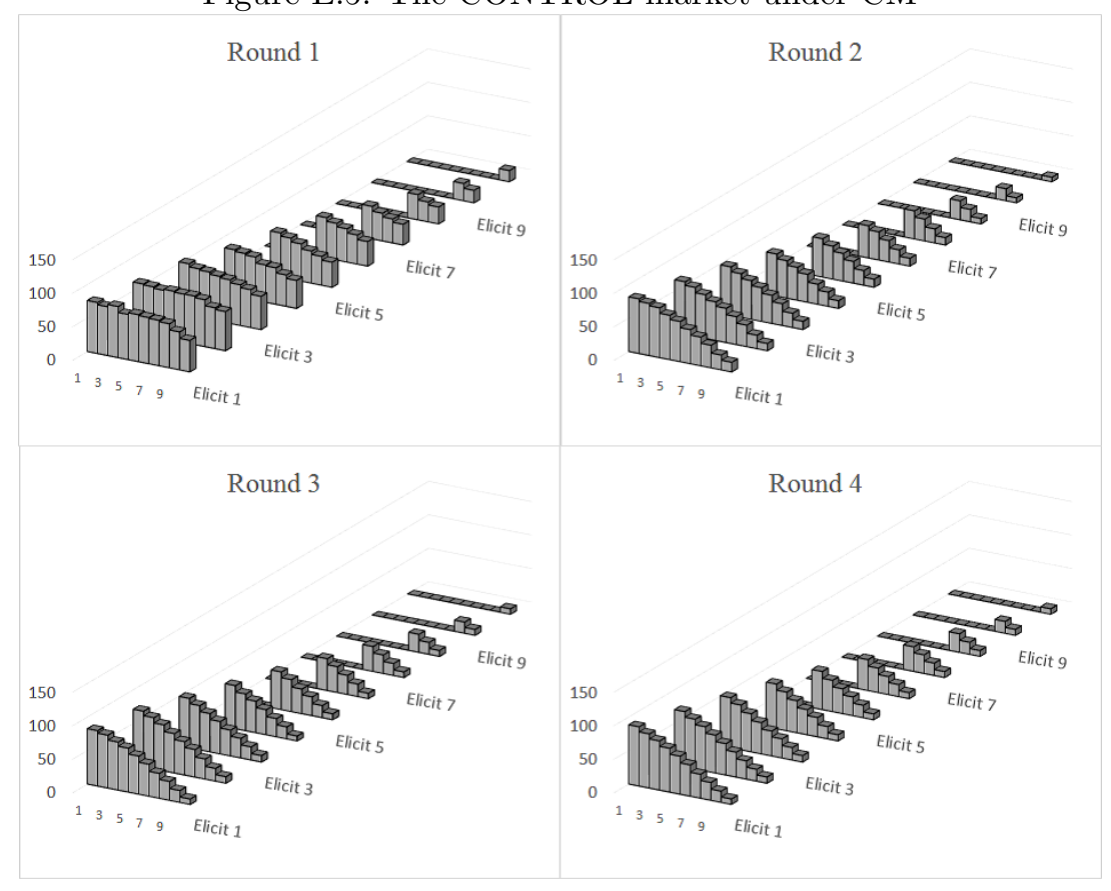


Figure E.6: The SYMM market under CM

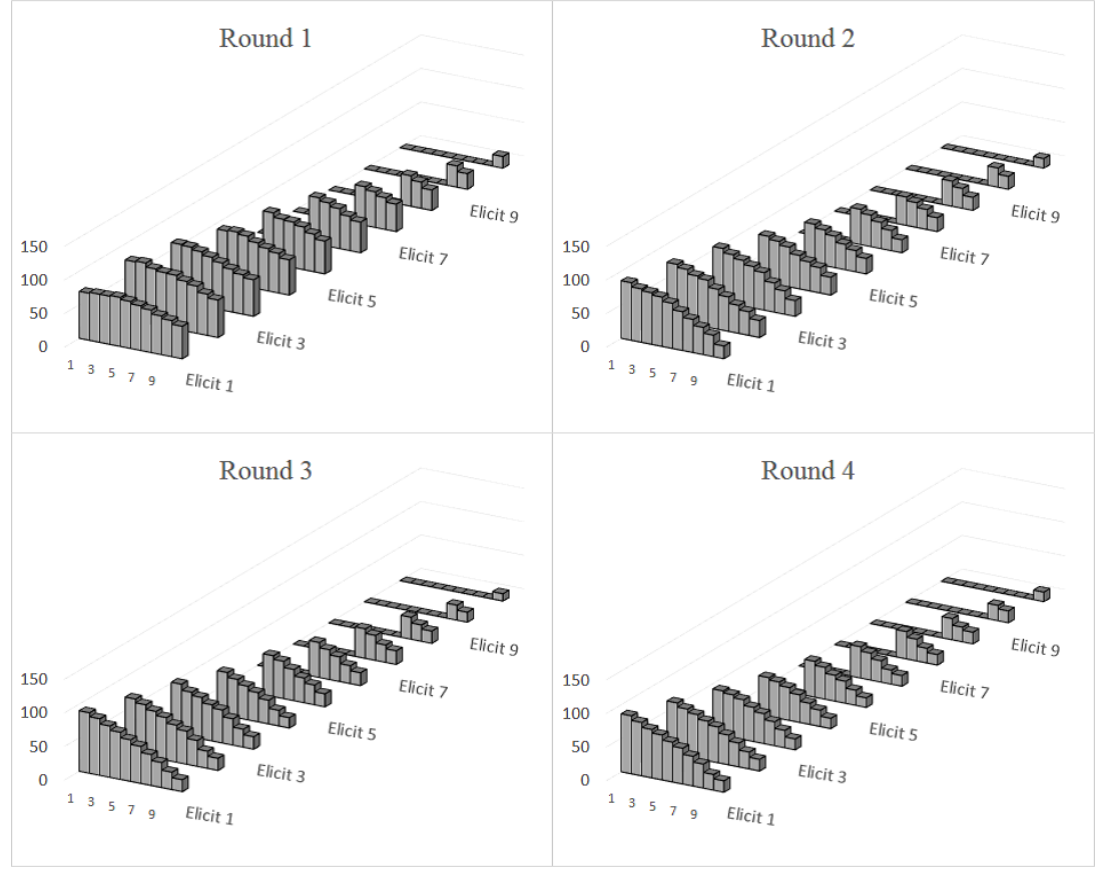

Figure E.7: The ASYMM market under CM (information level 0)

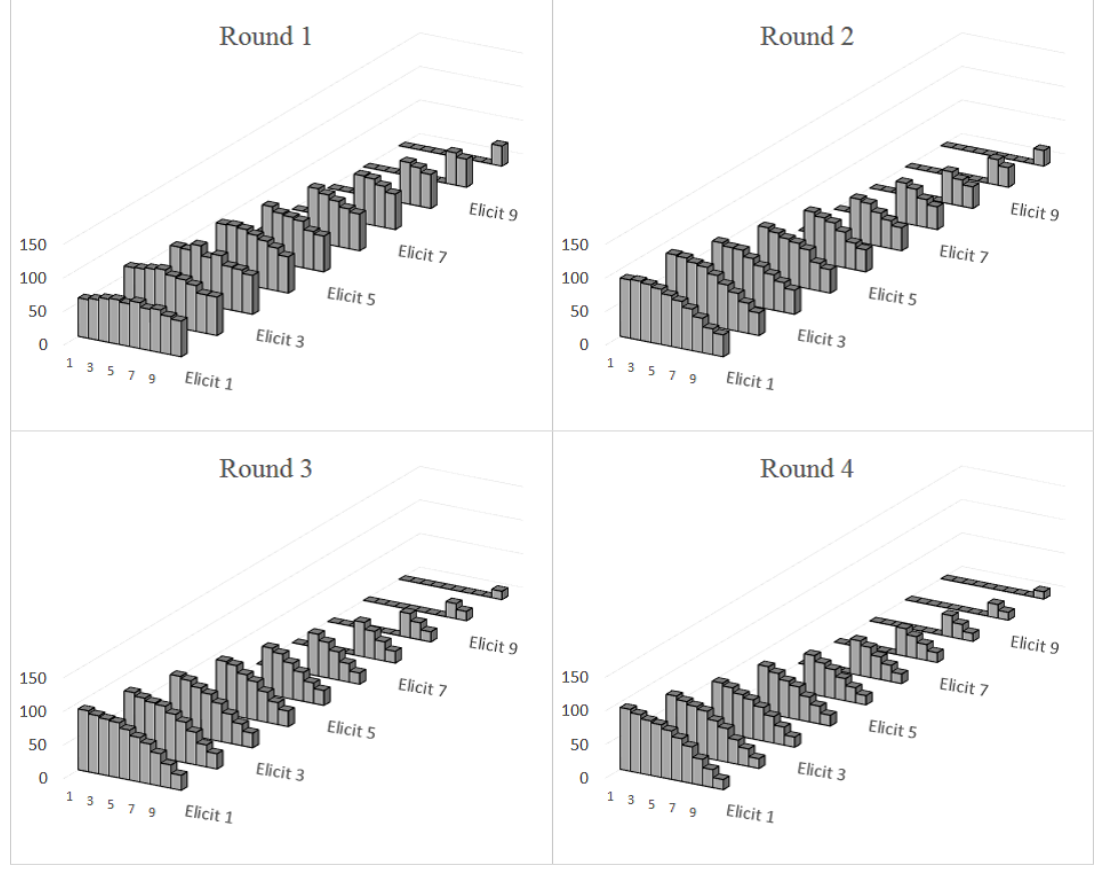


Figure E.8: The ASYMM markets under CM (information level 1)

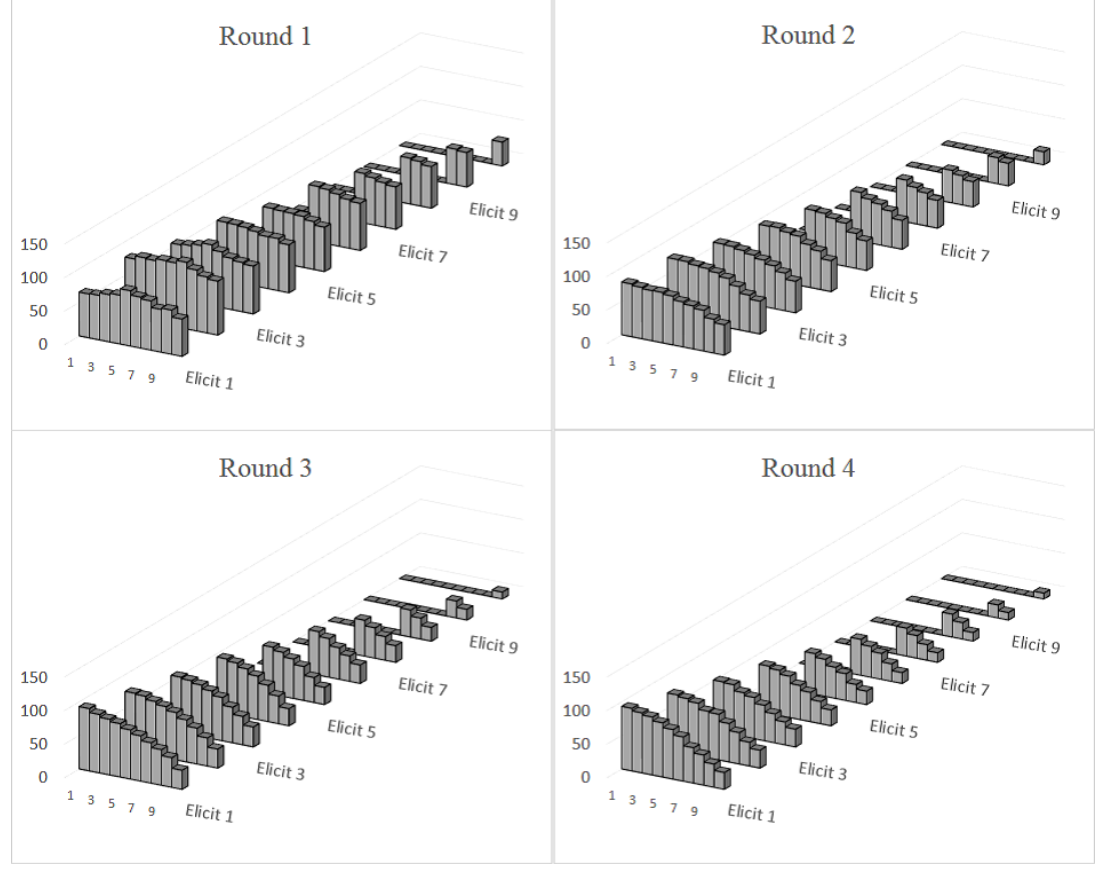

